

\title{
The surface properties of SOA generated from limonene and toluene using specific molecular probes: exploration of a new experimental technique
}

B. Demirdjian, M. J. Rossi

\section{- To cite this version:}

B. Demirdjian, M. J. Rossi. The surface properties of SOA generated from limonene and toluene using specific molecular probes: exploration of a new experimental technique. Atmospheric Chemistry and Physics Discussions, 2005, 5 (1), pp.607-654. hal-00303832

\section{HAL Id: hal-00303832 \\ https://hal.science/hal-00303832}

Submitted on 11 Feb 2005

HAL is a multi-disciplinary open access archive for the deposit and dissemination of scientific research documents, whether they are published or not. The documents may come from teaching and research institutions in France or abroad, or from public or private research centers.
L'archive ouverte pluridisciplinaire HAL, est destinée au dépôt et à la diffusion de documents scientifiques de niveau recherche, publiés ou non, émanant des établissements d'enseignement et de recherche français ou étrangers, des laboratoires publics ou privés. 


\section{The surface properties of SOA generated} from limonene and toluene using specific molecular probes: exploration of a new experimental technique

B. Demirdjian ${ }^{1^{*}}$ and M. J. Rossi ${ }^{1}$

${ }^{1}$ EPFL (Ecole Polytechnique Fédérale de Lausanne), LPAS (Laboratoire de Pollution Atmosphérique et Sol), $\mathrm{CH}-1015$ Lausanne, Switzerland

"Present address: CRMC-N/CNRS, Campus de Luminy, Case 913, 13288 Marseille cedex 09, France

Received: 13 December 2004 - Accepted: 13 January 2005 - Published: 11 February 2005 Correspondence to: M. J. Rossi (michel.rossi @epfl.ch)

(c) 2005 Author(s). This work is licensed under a Creative Commons License.

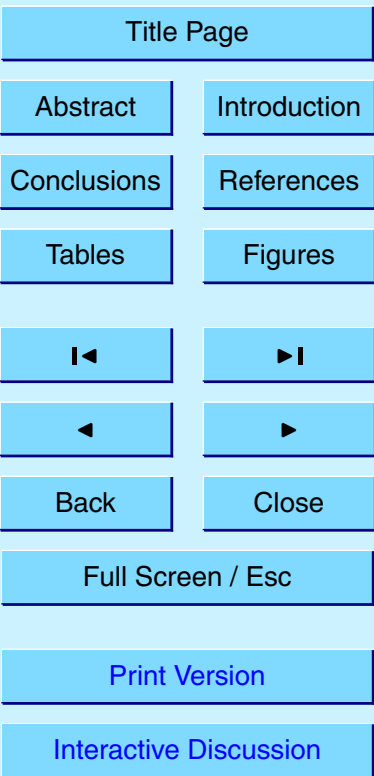




\section{Abstract}

A new experimental technique of characterizing the aerosol-atmosphere surface has been explored using three examples: the secondary organic aerosols (SOA) resulting from the reaction of limonene with $\mathrm{O}_{3}$ and from the photooxidation of toluene in 5 comparison with the combustion aerosol (soot) from a toluene diffusion flame. Rather than investigating the bulk composition of the aerosol by complete chemical analysis and identification of the many dozens if not more of constituent compounds we have interrogated the type and number of functional groups located at the aerosol surface by interacting them with specific molecular probes such as $\mathrm{O}_{3}, \mathrm{NO}_{2}, \mathrm{~N}\left(\mathrm{CH}_{3}\right)_{3}$, and $\mathrm{NH}_{2} \mathrm{OH}$ 10 to probe for the presence of oxidizable sites, acidic sites and carbonyl functionalities, respectively, that are present on the surface of the aerosol particle. In practice, typical amounts of one to a few mg of laboratory-generated SOA of limonene, toluene and soot have been deposited on a PTFE membrane filter that subsequently has been transferred to a molecular flow reactor used for the titration reaction of the surface functional groups by the molecular probes. Absolute amounts $\mathrm{N}_{i}$ with $\mathrm{i}=\mathrm{O}_{3}, \mathrm{NO}_{2}, \mathrm{~N}\left(\mathrm{CH}_{3}\right)_{3}$, $\mathrm{NH}_{2} \mathrm{OH}$ of probe molecules taken up by the filter sample measured using molecular beam sampling mass spectrometry have been converted into the number of surface group functionalities per unit surface area $S$ using the aerosol particle distribution function (PDF) of limonene and toluene SOA and the BET total surface area of toluene flame soot to result in $\mathrm{N}_{i} / \mathrm{S}$. Arguments are presented that support the transfer of the PDF of the suspended to the aerosol collected on the Teflon filter.

\section{Introduction}

Atmospheric particles occur in all strata of the atmosphere from the planetary boundary layer to the middle stratosphere and affect the atmosphere in a variety of ways and indirectly affect radiative forcing and the hydrological cycle whereas they have a

ACPD

5, 607-654, 2005

A new experimental technique for determining the SOA surface properties

B. Demirdjian and M. J. Rossi

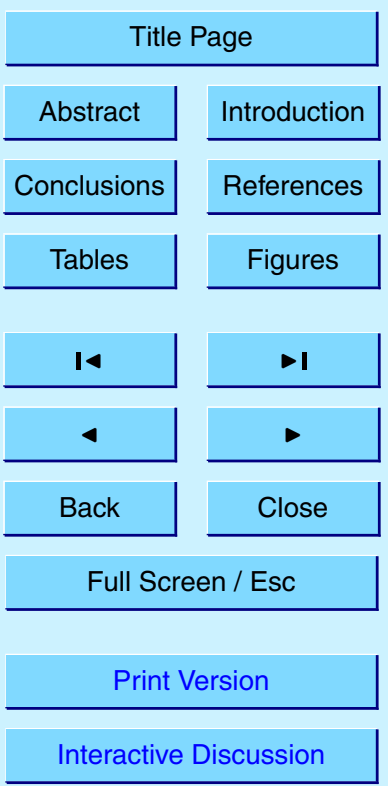


primary role in air pollution and control of atmospheric composition, visibility and human health on a regional and local scale (Haywood and Boucher, 2000; Ramaswamy et al., 2001; Ramanathan et al., 2001; Künzli et al., 2000). For instance their role in climate change has been brought to the fore because of the large persistent uncertainties 5 concerning the impact of aerosols on the radiative forcing owing to the lack of information (Ravishankara, 1997) on their chemical composition and critical gaps in scientific understanding of the gas-to-particle processes and chemical transformation mechanisms involved (Ramaswamy et al., 2001; Ravishankara, 1997). Atmospheric aerosols affect the radiation budget directly by scattering and absorbing solar and planetary ra- diation and indirectly by acting as cloud condensation nuclei that consist of particles larger than $50 \mathrm{~nm}$ in radius (Novakov et al., 1997; Facchini et al., 1999b). The radiative forcing of aerosols not only depends on their spatial distribution, but also on the size, shape, and chemical composition that control their optical properties (Ramaswamy et al., 2001).

15 Far from the emission sources these atmospheric particles are for the most part not homogeneous in nature and usually present complex structural and chemical features that are caused by their origin, history, lifetime, aging processes and their exposure to atmospheric trace gases. Widespread occurrence of organic and inorganic species which are often mutually and homogeneously mixed within the same particle and thus constitute internal rather than external mixtures (Middlebrook et al., 1998; Noble and Prather, 2000; Allan et al., 2003) implies a general presence of an organic chemical fraction within individual atmospheric particles (Novakov and Corrigan, 1996; Jacobson et al., 2000; Charlson et al., 2001; Andreae, 2001; Rudich, 2003). For instance, organic coatings may form on inorganic particles such as sea salt and mineral dust (Cruz and

25 Pandis, 1998; Posfai et al., 1998; Ellison et al., 1999). In some cases these organic coatings profoundly affect particle hygroscopicity, heterogeneous chemical reactivity and transport properties of aerosols (Saxena et al., 1995; Decesari et al., 2003).

This work is focused on Secondary Organic Aerosol (SOA) because a considerable fraction of atmospheric aerosols (10-60\%) contains organic compounds (Novakov and
ACPD

$5,607-654,2005$

A new experimental technique for determining the SOA surface properties

B. Demirdjian and M. J. Rossi

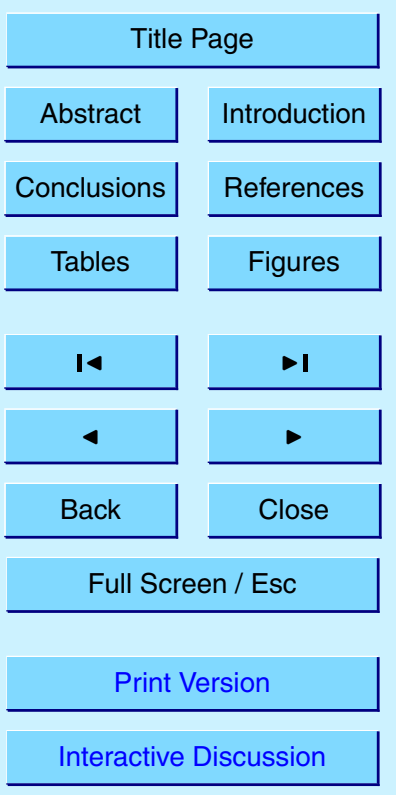


Corrigan, 1996; Jacobson et al., 2000; Charlson et al., 2001; Andreae, 2001; Rudich, 2003; Seinfeld and Pandis, 1998). On a global scale the SOA burden from oxidation of biogenic hydrocarbons is comparable to the one predicted from black carbon, nitrate and ammonium aerosols (Griffin et al., 1999). Moreover, the inorganic aerosol 5 fraction is relatively well investigated, whereas the composition and processes of formation of the organic fraction are not as well known. In fact, the analytical task of discovering the detailed chemical composition of the organic fraction of atmospheric aerosols remains a daunting and challenging task to this day (Middlebrook et al., 1998; Noble and Prather, 2000; Allan et al., 2003; Tobias and Ziemann, 2000) despite the re10 cent advances in analytical techniques in regards to atmospheric particulate analysis such as aerosol mass spectrometry (AMS) and thermal desorption chemical ionization mass spectrometry (TDCIMS) (Zhang et al., 2004; Smith et al., 2004). Prevailing scientific opinion has it that a detailed analytical investigation of the bulk composition of aerosol particles is a necessary prerequisite for the fundamental understanding of gas-to-particle conversion processes. This work intends to show an alternate path at characterizing only a small albeit relevant part of the chemical composition of SOA, namely that fraction that is directly interacting with the atmosphere at the surface of the particle.

SOA precursors have primary sources such as hydrocarbon or wax emissions from vegetation, combustion, biomass burning or sea spray carrying organic material from the ocean's surface. Alternatively, SOA may form in situ by photochemical oxidation reactions of gas phase organics involving $\mathrm{OH}, \mathrm{O}_{3}$ and $\mathrm{NO}_{3}$ which will result in low-vapor pressure oxygen-containing compounds that either form new particles in gas-to-particle conversion processes (Tobias and Ziemann, 2000; Odum et al., 1997; Facchini et al., 25 1999a; Pankow, 1998) or condense on existing airborne or seed particles through heterogeneous nucleation (O'Dowd et al., 2002a, b). While it seems clear that biogenic VOC contribute to organic aerosol mass, their role in the process of new particle formation is still uncertain. There is evidence from field observations that monoterpene oxidation products are linked to growth rather than to formation of new particles during

\section{A new experimental technique for determining the SOA surface properties}

B. Demirdjian and M. J. Rossi

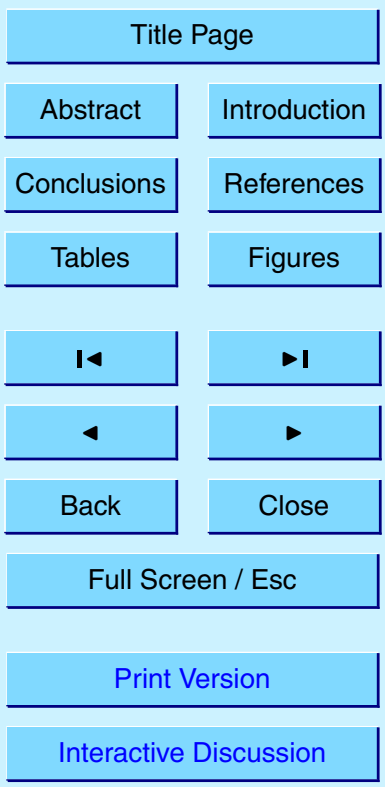


gas-to-particle formation processes (Janson et al., 2001). The resulting aerosols may also provide reactive sites for heterogeneous reactions (Ravishanakra, 1997) that can modify the oxidative capacity of the troposphere. In order to understand the mechanisms involved in such reactions characterization of the organic content and the degree 5 of partial oxidation of the constituent hydrocarbons owing to the oxidizing atmosphere would be beneficial.

\section{Scope of the present work}

The present work intends to show a possible way to characterize the surface functional groups of aerosol particles generated under well-controlled laboratory conditions as these functional groups either interact with atmospheric gases or the condensed phase such as solid mineral supports or biological membranes. In order to identify and quantify these functional groups we have chosen a titration technique using a gasphase probe molecule undergoing a specific heterogeneous chemical reaction. For demonstration purposes we have chosen the following four specific probes: $\mathrm{O}_{3}, \mathrm{NO}_{2}$, $\mathrm{N}\left((\mathrm{CH})_{3}\right)_{3}$, and $\mathrm{NH}_{2} \mathrm{OH}$ to probe for the presence of oxidizable sites, acidic sites and carbonyl functionalities, respectively. This allows us to characterize with great specificity the surface of laboratory generated organic aerosol surrogates using gas-phase probes rather than the examination of the particle composition. This approach is by no means a substitute for rigorous analytical work performed on SOA aimed at complete characterization of the particle composition which presents useful clues as to its origin and atmospheric aging processes. However, it leaves open the question which part of the SOA particle interacts with the gas phase on a given time scale (Jacobson et al., 2000; Rogge et al., 1993).

Such rigorous analytical work is necessary and must continue in the framework of 25 unraveling the precursors to and the mechanism of SOA formation. Our approach attempts to answer the question regarding the molecular composition of the aerosol particle surface that is the gateway to the interaction between the aerosol particle and

ACPD

5, 607-654, 2005

\section{A new experimental technique for determining the SOA surface properties}

B. Demirdjian and M. J. Rossi

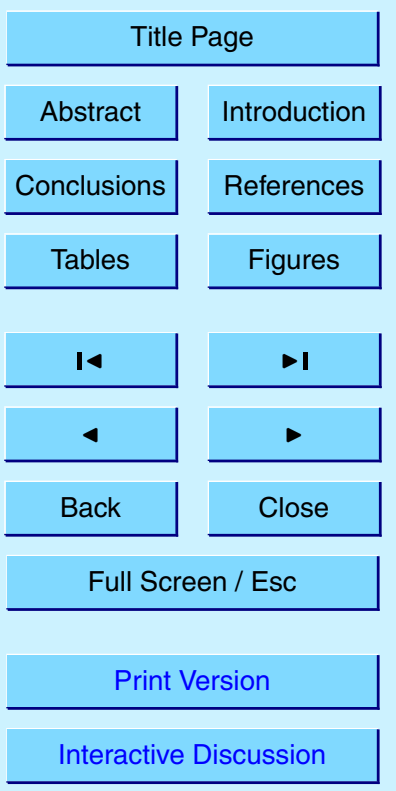


atmospheric gases on the one hand, and on the other hand determines the bonding of the aerosol particles to mineral and biological supports such as bacterial membranes and biological tissue.

The main focus of the present work is the demonstration of the surface-specific prob5 ing technique using a stable and reproducible source of laboratory-generated aerosol particles of some relevance to the atmosphere. The monoterpene limonene $\left(\mathrm{C}_{10} \mathrm{H}_{16}\right)$ has been chosen as a SOA precursor for this study in view of its high yield for SOA formation (Griffin et al., 1999) as well as its known oxidation product spectrum, reaction kinetics and mechanism in both $\mathrm{O}_{3}$ and $\mathrm{OH}$-induced oxidation reactions (Larsen 10 et al., 2001; Rohr et al., 2003; Liu et al., 2004). We have chosen toluene $\left(\mathrm{C}_{7} \mathrm{H}_{8}\right)$ as an anthropogenic VOC since it is the most abundant aromatic compound in urban air whose source may be traced back to the evaporation of fuel additives and the use of aromatic solvents. Typically, it corresponds to approximately $6 \%$ of the concentration of the observed non-methane hydrocarbons (Jeffries, 1995). In addition, toluene is the aromatic hydrocarbon with the highest aerosol-forming potential of whole gasoline vapors which was established in a study that suggested that the aromatic content was solely responsible for a fuel's SOA forming potential (Odum et al., 1997). As a comparison with toluene SOA from photooxidation we examine the interfacial properties of a combustion aerosol using toluene as a fuel in order to compare the interfacial

\section{Description of the experimental apparatus and procedures}

\subsection{Aerosol generation}

The principal goal of this section is to describe the aerosol generation using a highyield, reliable and stable aerosol source for the following surrogate aerosol particle characterization experiments. SOA particles are generated from the oxidation of limonene in the presence of $\mathrm{O}_{3}$ at one atmosphere of humid air (90\% rh) and from

ACPD

5, 607-654, 2005

\section{A new experimental technique for determining the SOA surface properties}

B. Demirdjian and M. J. Rossi




the photooxidation of toluene under similar conditions using a UV lamp (150W highpressure $\mathrm{Hg} / \mathrm{Xe}$ arc lamp in an AMKO type 1000 water cooled lamphousing equipped with a parabolic mirror). The IR radiation emitted by the $\mathrm{Hg} / \mathrm{Xe}$ arc was filtered out by a $8 \mathrm{~cm}$ pathlength circulating water filter equipped with two $2^{\prime \prime}$ diameter quartz win5 dows such that the temperature in the aerosol reactor was measured as $296 \pm 2 \mathrm{~K}$. The UV radiation was filtered using a $3 \mathrm{~mm}$ thick long-pass UV cut-off filter that presented a transmission of $50 \%$ at $280 \mathrm{~nm}$ (WG 280 , Schott). The SOA production takes place in a cylindrical reaction cell (volume $\cong 480 \mathrm{~cm}^{3}$ ) equipped with a $3^{\prime \prime}$ diameter quartz window at each end (Suprasil 2, HERAEUS) as displayed in Fig. 1. The typical concentra10 tions of limonene ( $\geq 96 \%$, FLUKA AG) and toluene (99\%, ALDRICH) are approximately $1000 \mathrm{ppm} . \mathrm{O}_{3}$ is generated in a flow discharge generator (ozone generator 502, FISCHER) and condensed at $198 \mathrm{~K}$ on silica-gel. The $\mathrm{O}_{3}$ concentration in the reaction cell, measured by UV absorption at $253 \mathrm{~nm}$, is on the order of $100 \mathrm{ppm}$. In order to prevent excessive oxidation of the freshly prepared aerosols by excess $\mathrm{O}_{3}$ a denuder 15 tube coated with $\mathrm{KI}$ was placed downstream of the flow reactor in order to disable continuous exposure of the SOA mass collected on the particle filter to ozone. Typical gas phase residence times within the flow reactor range from 0.5 to $2 \mathrm{~min}$ that were adjusted by changing the gas flow rate at an atmospheric pressure of air. The gas phase residence time downstream of the reactor within the tubing down to the filter 20 and the particle sizing equipment was typically a few seconds at the prevailing gas flow rates. Subsequently, the flow was passed across a PTFE membrane filter (MILLIPORE, $0.2 \mu \mathrm{m}$ pore diameter, $47 \mathrm{~mm}$ diameter) during one to two hours at constant flow rate leading to typical collected sample masses in the range of 1 to $10 \mathrm{mg}$. This type of filter was chosen in view of its lack of uptake of the probe molecules as well 25 as of the aerosol precursor hydrocarbons, namely limonene and toluene. Glass fiber filters (Schleicher \& Schuell, $47 \mathrm{~mm}$ diameter, type GF 6) had acidic sites that strongly interfered with the measurement of the number of acidic sites of the collected aerosol from limonene and toluene oxidation using $\mathrm{N}\left(\mathrm{CH}_{3}\right)_{3}$.

\section{A new experimental technique for determining the SOA surface properties}

B. Demirdjian and M. J. Rossi




The gas phase within the atmospheric pressure flow tube is monitored on-line using $5,607-654,2005$ a differentially pumped quadrupole mass spectrometer (BALZERS, Prisma QMS 200) equipped with an atmospheric sampling device. Figure 2 shows the details of the "on

5 line" detection chamber (Stadler, 2000a). The connection between the aerosol reactor and the mass spectrometer is enabled by a $25 \mathrm{~cm}$ long $100 \mu \mathrm{m}$ ID diameter quartz capillary (Fused silica tubing, SUPELCO). This capillary ends in a differentially pumped inlet valve pumped by a roughing pump (BALZERS GEV 010). Only a small fraction of the gas flow effuses through a flow-controlling orifice of $10 \mu \mathrm{m}$ diameter into the closed 10 ion source of the QMS that is located in the detection chamber. A turbomolecular pump maintains a low pressure in this chamber $\left(P \leq 5 \times 10^{-6} \mathrm{mbar}\right)$ in order to enable the use of the SEM detector of the mass spectrometer. Since we have noticed that during the aerosol formation the $10 \mu \mathrm{m}$ orifice of the differentially pumped valve is rapidly clogged by particles we have put a glass fiber filter in front of the $100 \mu \mathrm{m}$ inlet capillary at the 15 atmospheric pressure sampling position inside the aerosol reactor. In this way, most particles are retained by the filter and the gas phase monitoring may be performed unencumbered by the presence of semivolatile SOA particles.

During the aerosol generation the size distribution of SOA particles is monitored using a differential mobility analyzer (DMA, TSI Inc. Scanning Mobility Particle model 3071 A) coupled to a condensation nuclei counter (CNC, TSI Inc. model 3022 A). The total count performed using an identical CNC resulted in a number larger by a factor of two compared to the integral of the particle distribution function (PDF) measured using the DMA/CNC combination. Finally, FTIR Photoacoustic Spectroscopy (PAS) (MTEC photoacoustic cell, model 300) was used to identify the nature of the surface 25 functional groups of the aerosol particles deposited onto the filter used to support the SOA samples. A clean Teflon membrane filter was used as a blank. The SOA mass was routinely determined gravimetrically using an analytical balance prior to the uptake experiments performed in a Knudsen flow reactor.

\section{A new experimental technique for determining the SOA surface properties}

B. Demirdjian and M. J. Rossi

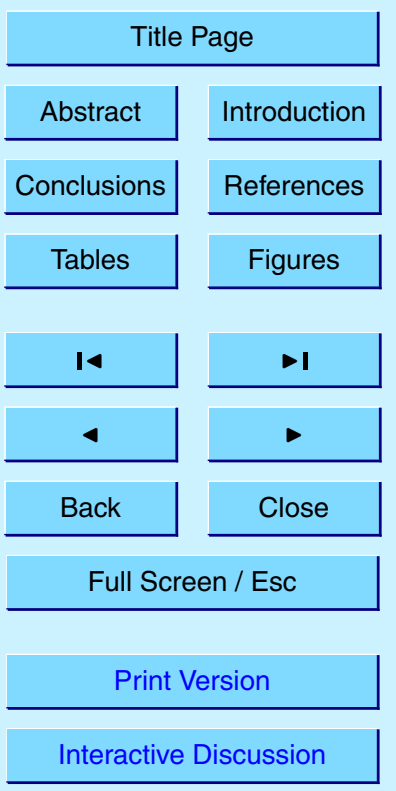


The soot samples are produced in a controlled and reproducible way from the combustion of liquid toluene in a diffusion flame using a co-flow air-fuel device that was operated on a fuel-rich flame leading to so-called "gray" soot. The device as well as the composition and properties of the "gray" soot are described in more detail in the 5 work of Stadler and Rossi (2000).

\subsection{Titration experiments}

Once the membrane filter was loaded with a measured amount of SOA or soot particles it was transferred immediately into the sample compartment of a Knudsen flow reactor (Stadler, 2000) and pumped using a roughing pump during approximately $90 \mathrm{~s}$ which directly pumps the sample chamber. Once the pressure was deemed to be low enough, say in the fractional $\mathrm{mb}$ range, molecular beam sampling could be initiated. The used titration technique makes use of a heterogeneous chemical reaction between the aerosol condensed phase supported on the filter and a gas-phase probe molecule whose nature determines the surface functional groups of the aerosol. The probe molecules used are ozone $\left(\mathrm{O}_{3}\right)$, nitrogen dioxide $\left(\mathrm{NO}_{2}\right)$, trimethylamine $\left(\mathrm{N}\left(\mathrm{CH}_{3}\right)_{3}\right)$, and hydroxylamine $\left(\mathrm{NH}_{2} \mathrm{OH}\right) . \mathrm{NO}_{2}$ (CARBAGAS) is diluted into oxygen (1:10) and stocked in darkness during approximately $14 \mathrm{~h}$ in order to convert traces of $\mathrm{NO}$ into $\mathrm{NO}_{2}$ that are always present as a contaminant. Subsequently, $\mathrm{NO}_{2}$ is frozen at approximately $193 \mathrm{~K}$ in a darkened vessel and $\mathrm{O}_{2}$ pumped off. $\mathrm{N}\left(\mathrm{CH}_{3}\right)_{3}$ was purchased from SIGMA-

ALDRICH (purum $\geq 99 \%$ ). Finally $\mathrm{NH}_{2} \mathrm{OH}$ is prepared by thermal decomposition of hydroxylammonium phosphate according to the method of Schenk (1963). Small aliquots of the solid salt were decomposed in the vacuum inlet line prior to use owing to the reactivity of free $\mathrm{NH}_{2} \mathrm{OH}$ with air.

\section{ACPD}

$5,607-654,2005$

\section{A new experimental technique for determining the SOA surface properties}

B. Demirdjian and

M. J. Rossi

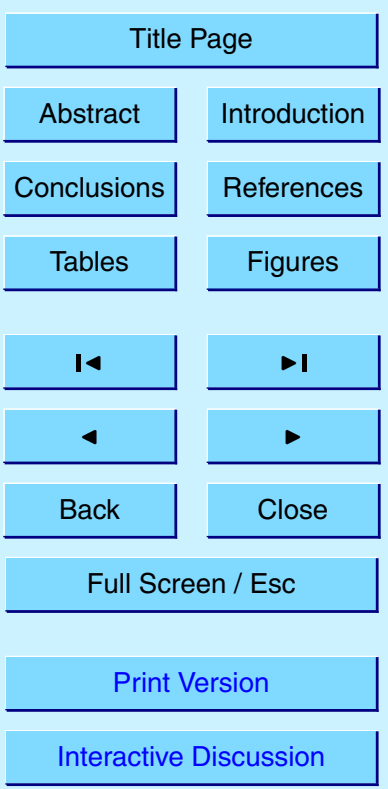




\section{Results and discussion}

4.1. SOA metrology

Once again we need to stress that the primary purpose of the present work is to explore the capabilities of the aerosol surface characterization technique using a stable 5 and reliable source of aerosols whose particle distribution function (PDF) is discussed in Appendix A. In this work we have chosen three types of aerosols based on the precursor hydrocarbons limonene and toluene, namely SOA of limonene and toluene as well as a combustion aerosol from a toluene diffusion flame.

\subsection{SOA yields}

10 The chemical mechanism of SOA formation under our experimental conditions is undoubtedly complex. No attempt was made to separate the effects of the individual oxidants $\mathrm{OH}, \mathrm{O}_{3}$ and $\mathrm{NO}_{3}$ on the precursor hydrocarbons as we are primarily interested in obtaining a SOA whose source was reliable and constant in order to explore the limits and scope of the proposed use of specific surface probes as a means of surface

characterization. The yield of SOA was taken as a measure for the aerosol-forming tendency of the hydrocarbon precursors under the chosen experimental conditions. The yield $Y_{S O A}$ was determined using Eq. (1):

$\mathrm{Y}_{S O A}=\mathrm{M}_{S O A} /\left(\left(\mathrm{F}^{i}-\mathrm{F}^{O}\right) \mathrm{MW}_{h c} \Delta t\right)$,

where $\mathrm{M}_{S O A}$ is the gravimetrically-determined mass of SOA after the deposition time $\Delta \mathrm{t}, \mathrm{MW}_{h c}$ is the molecular weight of the hydrocarbon precursor and $\mathrm{F}^{i}, \mathrm{~F}^{O}$ are the measured flow rates into and out of the aerosol flow reactor, respectively, in Mol per unit time.

During SOA formation we have simultaneously followed the gas phase concentration of the hydrocarbon precursor using an on-line residual gas mass spectrometer (MS) in order to establish a mass balance between the disappearance of the gaseous
ACPD

$5,607-654,2005$

A new experimental technique for determining the SOA surface properties

B. Demirdjian and

M. J. Rossi

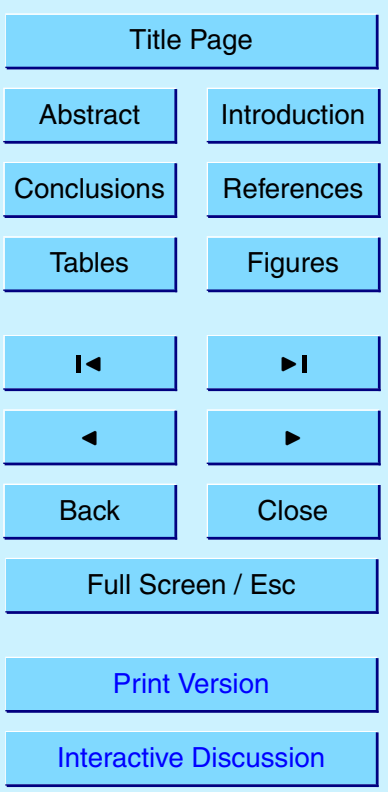


precursor and the collected mass of SOA. Figure 3a displays the limonene $\left(\mathrm{C}_{10} \mathrm{H}_{16}\right)$ ACPD flow rate $(\mathrm{Mol} / \mathrm{h})$ passing through the aerosol reactor as monitored by the MS-signal at $\mathrm{m} / \mathrm{e} 68$ as a function of time. Mass 68 is the base peak of limonene whose molecular ion is at $\mathrm{m} / \mathrm{e} 136$ and corresponds to $\mathrm{C}_{5} \mathrm{H}_{8}^{+}$, the mass of isoprene at half the mass of 5 limonene. We have reasons to believe that $\mathrm{m} / \mathrm{e} 68$ is a unique marker for limonene because its decrease upon $\mathrm{O}_{3}$ addition starting at $\mathrm{t}=500 \mathrm{~s}$ in Fig. 3a is larger (72\%) than the one for m/e 136 which corresponds to $44 \%$ as displayed in Fig. 3a. In addition, no other isomer of limonene has a significant MS amplitude at $\mathrm{m} / \mathrm{e} 68$ which is unusual in that it represents an even mass fragment upon electron impact ionization of a hydro10 carbon. Terpenes such as camphene, $\alpha$ - and $\beta$-pinene, $\Delta^{3}$-carene, $\beta$-myrcene and $\alpha$-phellandrene have been checked using information from the NIST Webbook (URL at http://webbook.nist.gov/chemistry/).

We imply that a reaction product formed in the SOA generation process contributes to a fragment ion at m/e 136 that partially offsets the decrease owing to chemical 15 reaction of limonene. This is also supported by the significant background MS signal at $\mathrm{m} / \mathrm{e} 136$ once the limonene flow has been shut off after the SOA generation has been halted, as displayed in Fig. $3 a$ at $t=3300$ s. However, we have no way to be sure at this time that there may also be a contribution of a fragment ion to the MS signal intensity at $\mathrm{m} / \mathrm{e} 68$ once SOA formation has started. Therefore, we regard $\mathrm{Y}_{S O A}$ as an upper limiting value. The addition of $\mathrm{O}_{3}$ at $\mathrm{t}=500 \mathrm{~s}$ marks the onset of SOA formation and thus of the decay of [limonene] as displayed by the decrease of the MS signal at m/e 68 to a steady-state level that is reached at $t=1000 \mathrm{~s}$ at $72 \%$ of the original level of MS signal. Figure 3a pertains to experiment LIM3 displayed in Table 1 with a measured value of $\mathrm{dM}_{S O A} / \mathrm{dt}=3.43 \mathrm{mg} / \mathrm{h}$ which leads to $\mathrm{Y}_{S O A}=0.55$. The decrease of $\mathrm{m} / \mathrm{e} 68$ leads to an 25 expected loss of precursor of $6.29 \mathrm{mg} / \mathrm{h}$. This loss is derived from the limonene partial pressure of 2 Torr at $10 \mathrm{ml} / \mathrm{min}$ and the $72 \%$ disappearance of the limonene MS signal at $\mathrm{m} / \mathrm{e} 68$. This loss is overestimated by approximately $5 \%$ because the gradual decline of the MS signal at $\mathrm{m} / \mathrm{e} 68$ has been approximated by an instantaneous drop. This will lead to a slight underestimation of $\mathrm{Y}_{S O A}$ on a mass basis and is certainly comparable

\section{A new experimental technique for determining the SOA surface properties}

B. Demirdjian and M. J. Rossi

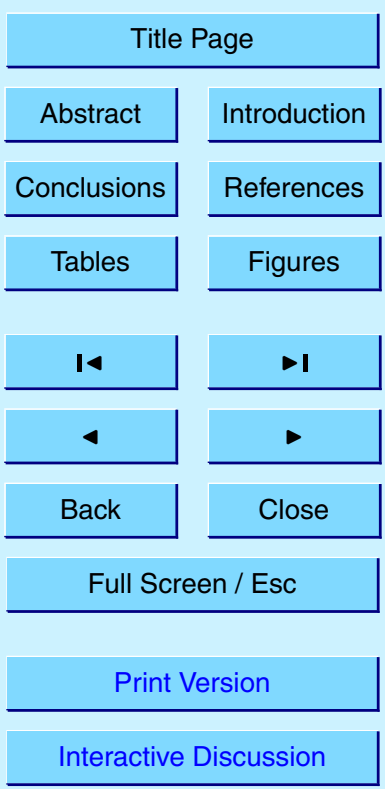


to, albeit at the higher end of literature values (Griffin et al., 1999; Larsen et al., 2001). It is a rough guide to characterize the SOA formation process.

Figure $3 \mathrm{~b}$ shows the decay of the toluene MS-signal by approximately $35 \%$ as soon as the UV lamp is switched on and corresponds to experiment TOL3 displayed in Ta5 ble 1 . The number of moles of toluene lost from the gas phase during photooxidation corresponds to $4.510^{-6} \mathrm{Mol} / \mathrm{h}$ corresponding to $0.41 \mathrm{mg} / \mathrm{h}$ based on $2 \mathrm{ml} / \mathrm{min}$ of toluene flow rate at a partial pressure of 2 Torr of toluene. Experimentally we obtain a yield $2.29 \mathrm{mg} / \mathrm{h}$ of SOA resulting in $\mathrm{Y}_{S O A}=5.59$ according to Eq. (5). Since $\mathrm{Y}_{S O A}$ is unusually high corresponding to a $559 \%$ yield on a mass basis we assume that the 10 additional mass collected on the filter stems from continuing reaction with both unreacted toluene and small concentrations of $\mathrm{O}_{3}$ and perhaps other reactive intermediates once the SOA has been deposited on the filter. We would like to point out, however, that most of the ozone has been taken out of the reactive flow by using the $\mathrm{KI}$ denuder upstream of the filter as displayed in Fig. 1, whereas toluene and other reactive gases 15 may still contribute to the observed mass increase. According to Fig. $3 b$ there remains at least $65 \%$ of unreacted toluene that may also contribute to $\mathrm{M}_{S O A}$. Molecular oxygen, $\mathrm{O}_{2}$ and/or $\mathrm{H}_{2} \mathrm{O}$ may also add to trapped reactive intermediates thereby increasing their mass. As in the case of limonene the gradual decline of the MS signal at m/e 92 has been approximated by an instantaneous drop which will lead to an underestimation of

$20 \mathrm{Y}_{S O A}$ by $5 \%$ or so. More importantly, the present value of $\mathrm{Y}_{S O A}$ for toluene may on the other hand represent an upper limit value which may result from the effect of fragment contributions of the complex hydrocarbon mixture in the aerosol flow reactor to m/e 92 . A lower limiting value of $\mathrm{Y}_{S O A}$ may be obtained by assuming total disappearance of the toluene MS signal at $\mathrm{m} / \mathrm{e} 92$ resulting in $\mathrm{Y}_{S O A}=1.9$ which is still high. High molecular 25 weight compounds have been interpreted by Bowman and Karamalegos (2002) as an indication that organic aerosol components are heavy and therefore of sufficiently low vapor pressure that they can partition out of the gas phase and condense under the chosen experimental conditions (Seinfeld et al., 2001).

\section{A new experimental technique for determining the SOA surface properties}

B. Demirdjian and M. J. Rossi

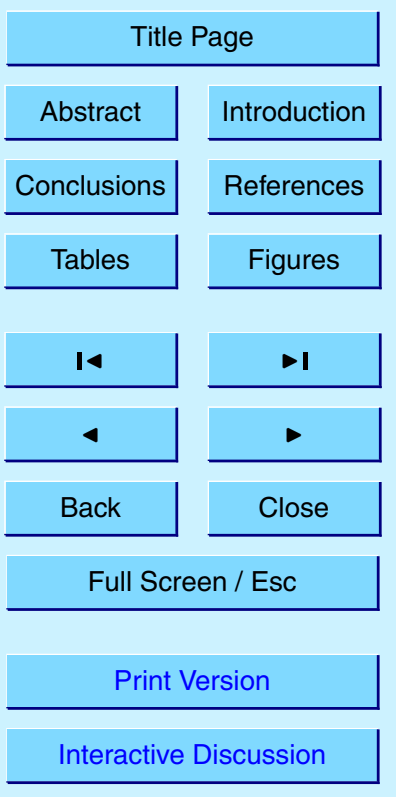


We have explored the capabilities and limitations of a chemical titration technique us$5,607-654,2005$ ing a gas-phase probe molecule undergoing a "heterogeneous chemical reaction" with surface functional groups located at the gas-condensed phase interface of the particle 5 in question. For that purpose we have used a Knudsen flow reactor using a specific gas phase probe molecule interacting with the aerosol particles that have been collected on a Teflon membrane filter. The property of the probe determines the surface functional groups of the aerosol surface that interact with the gas phase. The titration experiment is based on the measurement of the total number $\mathrm{N}_{i}$ of each type of probe molecule 10 i that is lost from the gas phase until no more probes are taken up. At saturation of the uptake the aerosol particle surface will be saturated with probe molecule I whose disappearance from the gas phase has been quantitatively measured. $\mathrm{N}_{i}$ will subsequently be related to a geometric parameter such as the surface area given for example by the aerosol mobility diameter resulting from the measured aerosol size distribution 15 function. This will enable the expression of the final result in terms of the surface density of different functional groups on the surface of the aerosol particle examined by the different probes of type i.

In order to detect the quantity of oxidizable sites we have used two oxidizing probe molecules such as $\mathrm{O}_{3}$ or $\mathrm{NO}_{2}$ in order to determine the number of oxidizable surface functionalities. Equation (2) schematically describes the reaction where $-\mathrm{C}_{r e d}$ and $-\mathrm{C}_{o x}$ correspond to an oxidizable and an oxidized surface site, respectively:

$-\mathrm{C}_{\text {red }}+\mathrm{O}_{3} / \mathrm{NO}_{2} \rightarrow-\mathrm{C}_{\mathrm{ox}}+\mathrm{O}_{2} / \mathrm{N}(\mathrm{II}$ or III)(HONO or $\mathrm{NO})$

We have chosen the base $\mathrm{N}\left(\mathrm{CH}_{3}\right)_{3}$ for the quantitation of acidic sites $-\mathrm{COOH}$ that are probed according to Eq. (3) and that result in the formation of a solid salt which is undetectable using MS. However, we cannot exclude small amounts of mineral acids to be present as potential impurities in the aerosol that would also contribute to the

A new experimental technique for determining the SOA surface properties

B. Demirdjian and M. J. Rossi

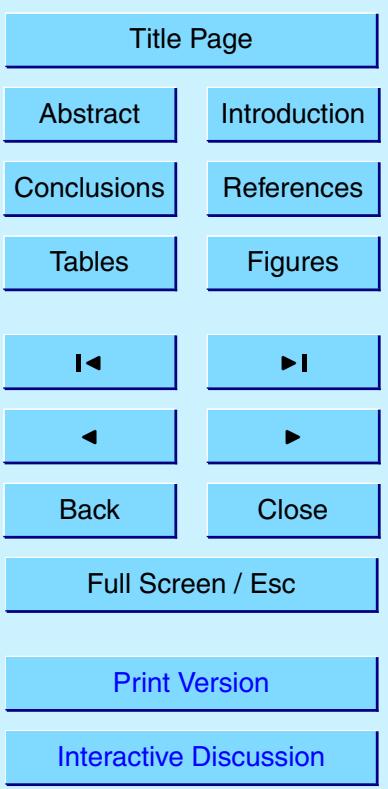


titration reaction:

$-\mathrm{COOH}+\mathrm{N}\left(\mathrm{CH}_{3}\right)_{3} \rightarrow-\mathrm{COO}^{-}\left(\mathrm{CH}_{3}\right)_{3} \mathrm{NH}^{+}$

$5,607-654,2005$

The free base hydroxylamine, $\mathrm{NH}_{2} \mathrm{OH}$, has been chosen for the detection of the abundance of surface carbonyl groups. We expect that $\mathrm{NH}_{2} \mathrm{OH}$ is forming an oxime $\mathrm{R}^{1} \mathrm{R}^{2}$ $5 \mathrm{C}=\mathrm{N}-\mathrm{OH}$ through a condensation reaction owing to a general acid-catalyzed reaction with surface-bound carbonyl groups of the SOA sample of the type $R^{1} R^{2}-C=O$ according to Reaction (4).

$\mathrm{R}^{1} \mathrm{R}^{2}-\mathrm{C}=\mathrm{O}+\mathrm{NH}_{2} \mathrm{OH} \rightarrow \mathrm{R}^{1} \mathrm{R}^{2}-\mathrm{C}(\mathrm{OH})(\mathrm{NHOH}) \rightarrow \mathrm{R}^{1} \mathrm{R}^{2}-\mathrm{C}=\mathrm{N}-\mathrm{OH}+\mathrm{H}_{2} \mathrm{O}$

Most probably the general acid-catalyzed condensation Reaction (4) also acts on surface functionalities other than aldehydic and ketone carbonyl groups such as esters, organic acids, amides, acid anhydrides and others. As such $\mathrm{NH}_{2} \mathrm{OH}$ is unable to distinguish between these possibilities without additional differentiating tests.

In addition to the surface carbonyl groups that are to be determined the presence of an acid seems to be mandatory to enable Reaction (4). Control experiments with 15 solid thin films of xanthone $\left(\mathrm{C}_{13} \mathrm{H}_{8} \mathrm{O}_{2}\right)$, a solid aromatic ketone, that did not contain an acid indeed did not undergo an uptake reaction with $\mathrm{NH}_{2} \mathrm{OH}$. Reference experiments conducted on a thin deposited film of xanthone that previously had been exposed to gas phase $\mathrm{HCl}$ in situ did not take up $\mathrm{NH}_{2} \mathrm{OH}$ at all. Instead, when $\mathrm{HCl}$ reacted with $\mathrm{NH}_{2} \mathrm{OH}$ in the gas phase by letting in a separate flow of both $\mathrm{HCl}$ and $\mathrm{NH}_{2} \mathrm{OH}$ a rapid rate of disappearance of both $\mathrm{NH}_{2} \mathrm{OH}$ and $\mathrm{HCl}$ was observed, presumably forming the solid salt $\mathrm{NH}_{3} \mathrm{OH}^{+} \mathrm{Cl}^{-}$that was not observed using MS. Unfortunately, the photoacoustic FTIR absorption technique discussed in Appendix $B$ in more detail is not sensitive enough for the identification of the reaction products of the titration reactions. For instance, oximes that specifically absorb between 1640 and $1690 \mathrm{~cm}^{-1}(\mathrm{C}=\mathrm{N}$ stretching vibration) generally lack strong characteristic absorptions throughout the IR spectrum (Williams and Fleming, 1971).

The use of the Knudsen flow reactor is an excellent method for establishing the total number of molecules lost from the gas phase because of adsorption and/or re-

\section{A new experimental technique for determining the SOA surface properties}

B. Demirdjian and

M. J. Rossi

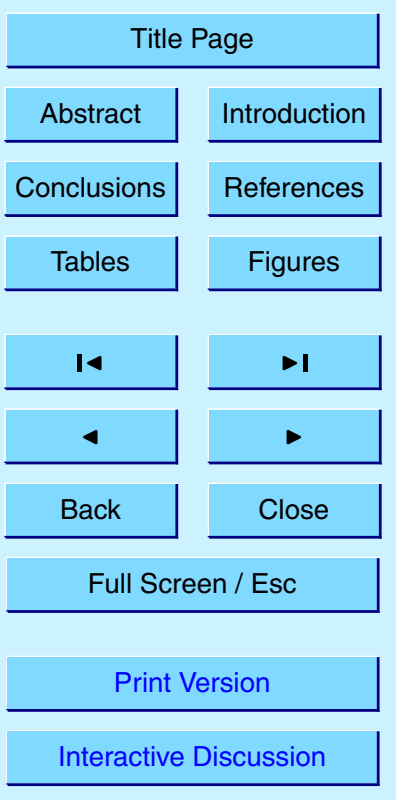


action (Caloz et al., 1997). The absolute number of probe molecules taken up by the supported aerosol collected on the Teflon membrane filter is measured after suitable calibration of the MS. This number is subsequently put in relation to the structural parameters given by the measured particle distribution function (PDF) of the collected 5 aerosol. Below we will present experimental evidence that the PDF of the sampled aerosol remains unchanged under certain experimental conditions after collection on the filter. Each titration consists of a pair of uptake experiments in which the number of molecules taken up by the loaded Teflon membrane filter is compared to the uptake of the probe gas on a blank filter, thereby assuming that the uptake of the probe gas does 10 not change from one filter specimen to the next. This has been checked by comparing a series of blank filter runs using a particular probe gas molecule. Therefore, the net number of molecules taken up by the collected aerosol has been obtained using Eq. (5) where $\mathrm{N}_{i}$ (aerosol + filter) and $\mathrm{N}_{i}$ (filter) are the number of molecules of a particular probe i taken up to saturation by the loaded and the blank filter, respectively. In 15 view of the light mass loading of the filter Eq. (5) was shown to be appropriate as will be discussed below.

$\mathrm{N}_{i}($ aerosol $)=\mathrm{N}_{i}($ aerosol + filter $)-\mathrm{N}_{i}($ filter $)$

A typical titration experiment based on the uptake of a probe gas molecule is illustrated in Fig. 4. The time-dependent $\mathrm{MS}$ signal of $\mathrm{O}_{3}$ at $\mathrm{m} / \mathrm{e} 48, \mathrm{~F}_{O 3}^{i}$, at $1.5 \mathrm{~V}$ corresponds 20 to a flow rate of $2.0 \times 10^{15}$ molecule $\mathrm{s}^{-1}$ before the start of the uptake experiment, that is in the absence of the aerosol sample, in which ozone probes for the oxidizable sites on toluene soot. The MS signal $\mathrm{F}_{\mathrm{O}_{3}}(\mathrm{t})$ in the presence of the aerosol sample is proportional to the rate of effusion of surviving probe molecules whose flow decreases at approximately $100 \mathrm{~s}$ at the start of the uptake experiment owing to the interaction of $\mathrm{O}_{3}$ with the deposited toluene soot aerosol during the gas phase residence time of approximately $30 \mathrm{~s}$ in the flow reactor. During the reaction the integration of the difference signal corresponding to the hatched area displayed in Fig. 4 directly obtains the number of probe molecules lost from the gas phase in the presence of the supported
ACPD

$5,607-654,2005$

\section{A new experimental technique for determining the SOA surface properties}

B. Demirdjian and M. J. Rossi

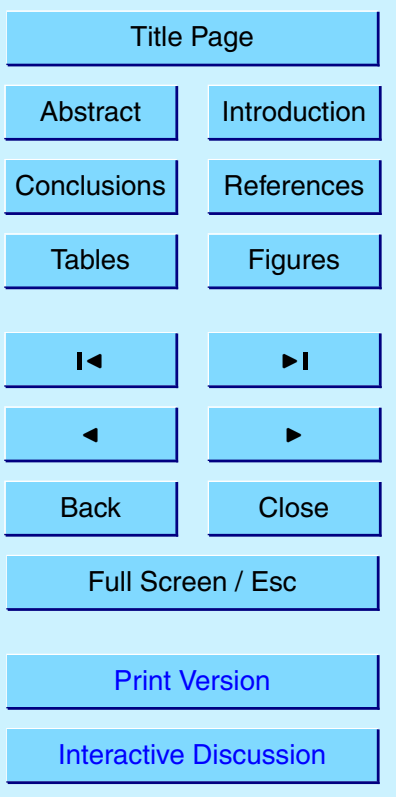


aerosol after the flow has been calibrated in molecule $\mathrm{s}^{-1}$. The difference of $\mathrm{O}_{3}$ flows with (lower MS signal, $\mathrm{F}_{O_{3}}(\mathrm{t})$ ) and without (horizontal line at constant flow rate, $\mathrm{F}_{\mathrm{O}_{3}}^{i}$ ) reactive substrate therefore corresponds to the quantity of molecules taken up owing to the probing reaction and equals the number of sites of the aerosol sample that inter5 acts with a given probe. This difference corresponds to $\mathrm{N}_{i}($ aerosol + filter) and is given by Eq. (6):

$\mathrm{N}_{i}($ aerosol + filter $)=\int\left(\mathrm{F}_{\mathrm{O}_{3}}^{i}-\mathrm{F}_{\mathrm{O} 3}(\mathrm{t})\right) \mathrm{dt}$

A reference experiment that is identical to the one presented above but without aerosol on the Teflon filter yields a value for $\mathrm{N}_{i}$ (filter) that leads to $\mathrm{N}_{i}$ (aerosol) according to

10 Eq. (5). This value essentially corresponds to a double difference and is the parameter of interest that is related to the aerosol structural parameters obtained form the PDF presented above. We have used $\mathrm{O}_{3}, \mathrm{NO}_{2}, \mathrm{~N}\left(\mathrm{CH}_{3}\right)_{3}$, and $\mathrm{NH}_{2} \mathrm{OH}$ as probe molecules and have performed titration experiments both on limonene and toluene SOA as well as toluene flame soot particles, all supported on Teflon filters. Typical results are displayed in Table 1.

\subsubsection{Metrology of supported SOA of limonene and toluene collected on the Teflon} membrane filter

The necessity for integration of the aerosol concentration in order to achieve a sufficient yield of the collected aerosol for interrogation by the molecular probes in the Knudsen flow reactor raises the question whether the PDF measured for suspended aerosols is preserved or not once the aerosol has accumulated on the Teflon membrane filter. The measurement of the PDF is performed on suspended aerosol at 1 or 2 min residence time (age) whereas the collected aerosol is interrogated using the probes after accumulation over one to two hours which corresponds to a time scale longer by roughly two orders of magnitude. Experiments LIM4, 5 and 6 displayed in Table 1 have been performed in order to investigate the dependence of $\mathrm{N}_{i}$ (aerosol) on $\mathrm{M}_{S O A}$ of limonene for $\mathrm{i}=\mathrm{N}\left(\mathrm{CH}_{3}\right)_{3}$. Figure 5 shows this dependence to be linear as is the dependence of
ACPD

5, 607-654, 2005

A new experimental technique for determining the SOA surface properties

B. Demirdjian and M. J. Rossi

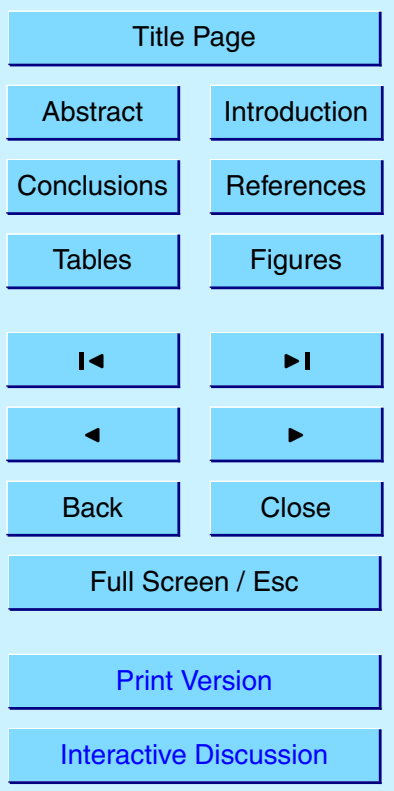


the uptake coefficient of $\mathrm{N}\left(\mathrm{CH}_{3}\right)_{3}$ on the collected limonene SOA, expressed on a relative scale as $\mathrm{k}_{u n i} / \mathrm{k}_{e s c}$, the values of which are displayed in the last column of Table 1. Equation (7) establishes that the relative rate constant $\mathrm{k}_{u n i} / \mathrm{k}_{e s c}$ for the uptake of the probe with an uptake coefficient $\gamma$ on a surface $S$ of the aerosol in a Knudsen flow 5 reactor whose area of the exit orifice is $A$ is proportional to $S$ :

$\mathrm{k}_{\text {uni }} / \mathrm{k}_{\text {esc }}=\gamma(\mathrm{S} / \mathrm{A})$

Figure 5 displays the linear relationship of $S$ of the collected aerosol with SOA mass $\mathrm{M}_{S O A}$ which leads to the important conclusion that the limonene SOA has a constant surface to mass or volume ratio under the chosen experimental conditions which is 10 proportional to the slope of the straight line. The result that $\mathrm{N}_{i}$ (aerosol) corresponding to the integral number of probe molecules that interact with the aerosol surface also scales with SOA mass $\mathrm{M}_{S O A}$ as displayed in Fig. 5 means that $\mathrm{N}_{i}$ (aerosol) scales with the surface-to-mass or surface-to-volume ratio $S / V$ of the aerosol, provided the aerosol density is constant with $\mathrm{M}_{S O A}$. The constant $\mathrm{S} / \mathrm{V}$ ratio of the aerosol across the explored 15 range of $\mathrm{M}_{S O A}$ also means that the PDF of the collected SOA remains constant with $\mathrm{M}_{S O A}$. Therefore, the collected aerosol particles do not undergo agglomeration and coalescence during deposition which would ordinarily lead to a change of the PDF. This result has been obtained by means of the surface sensitive uptake kinetics given in Eq. (7) and provides the justification to use the PDF of the suspended aerosol for the 20 characterization of the collected aerosol, at least for filter loadings that are compatible with constant surface to volume ratios.

Experiments LIM9 and 10 for $\mathrm{i}=\mathrm{NH}_{2} \mathrm{OH}$ displayed in Table 1 is an additional example of this scaling behaviour that indicates the "freezing" of the PDF upon collection of the aerosol on a filter support as long as the aerosol mass loading of the filter is small. 25 However, experiments TOL1 and 4 for $\mathrm{i}=\mathrm{N}\left(\mathrm{CH}_{3}\right)_{3}$ shows scaling of $\mathrm{N}_{i}$ (aerosol) with $\mathrm{M}_{S O A}$ as the ratio $\mathrm{N}_{i} / \mathrm{M}_{S O A}$ displayed in column 8 of Table 1 is approximately constant over a 6.13-fold variation of $\mathrm{M}_{S O A}$, whereas $\mathrm{k}_{u n i} / \mathrm{k}_{e S C}$ increases only by a factor of 1.68. We assume that at the lowest mass loading $\mathrm{M}_{S O A}=0.8 \mathrm{mg}$ (experiment TOL4 of Table 1) the surface to volume ratio S/V of the collected aerosol is given by the PDF

\section{A new experimental technique for determining the SOA surface properties}

B. Demirdjian and M. J. Rossi

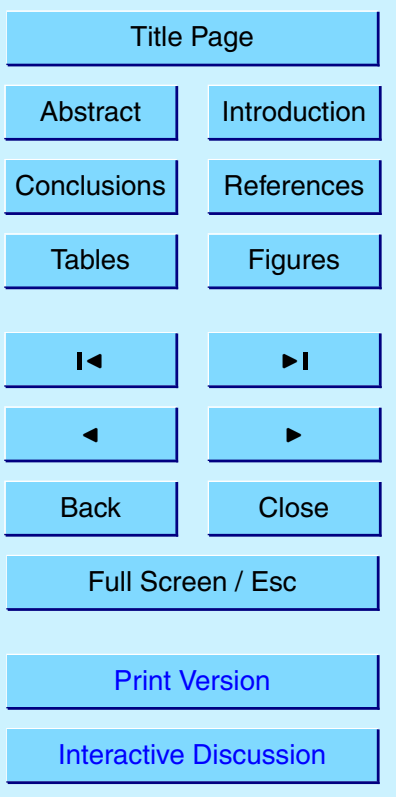


of the suspended aerosol measured at the exit of the aerosol reactor owing to the light mass loading of the toluene SOA. In contrast, the decrease of the S/V ratio by a factor of 3.6 at the highest mass loading of $4.9 \mathrm{mg}$ (experiment TOL1 of Table 1) compared to the expected value for $\mathrm{M}_{S O A}=0.8 \mathrm{mg}$ may indicate some agglomeration of the aerosol 5 upon collection. As discussed in Appendix A the PDF of the suspended SOA at the exit of the aerosol flow tube was constant during aerosol collection to an accuracy of the order of $10 \%$ as may be seen in Figs. A2a or A2b. We conclude therefore that the decrease in $S / V$ ratio must have occurred during aerosol collection. This goes to show that more work is needed in order to find experimental conditions that enable the 10 collection of SOA all the while preserving the S/V ratio of the suspended aerosol.

We therefore use the PDF obtained from the suspended aerosol in order to put the $\mathrm{N}_{i}$ (aerosol) values into perspective by normalizing it to unit surface area. When we calculate the number of particles that form a toluene SOA particle layer across the $17.3 \mathrm{~cm}^{2}$ geometrical surface area of the membrane filter using $488 \mathrm{~nm}$ as the effective 15 diameter of one aerosol particle whose justification will be discussed in more detail below we arrive at $17.3 /\left(\pi\left(244 \times 10^{-7}\right)^{2}\right)=9.2 \times 10^{9}$ particles trapped on the filter corresponding to $0.6 \mathrm{mg}$. However, Fig. 5 clearly indicates that mass loadings of $6 \mathrm{mg}$ of limonene SOA are still on the straight line with respect to both $\mathrm{N}_{\mathrm{N}(\mathrm{CH} 3)_{3}}$ (aerosol) as well as $\mathrm{k}_{\text {uni }} / \mathrm{k}_{\text {esc }}$. This means that in this case no loss of surface of the deposited aerosol occurs even at the highest mass loading of $6 \mathrm{mg}$ (experiment LIM6 displayed in Table 1) under the assumption of a geometrically flat filter which obviously is too much of a simplification. The assumption of an effective filter area larger than the geometric one is consistent with the specification of the Teflon membrane filter given by the manufacturer that claims a degree of $85 \%$ porosity consisting of $220 \mathrm{~nm}$ diameter pores. Table 2

\section{ACPD}

$5,607-654,2005$

\section{A new experimental technique for determining the SOA surface properties}

B. Demirdjian and M. J. Rossi

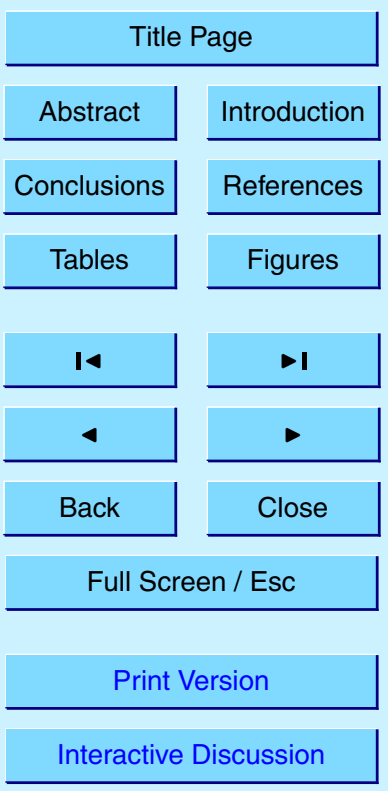


4.4. Evaluation of surface densities of functional groups $\mathrm{N}_{i}($ aerosol)/S for toluene soot aerosol

According to experiment SOOT1 displayed in Table 1 and Fig. 4 an average of $2 \times 10^{17}$ molecules of $\mathrm{O}_{3}$ were taken up per $\mathrm{mg}$ of toluene soot that may be repre5 sented by $\mathrm{N}_{O 3}$ (aerosol)/ $/ \mathrm{M}_{\text {aerosol. }}$. Although the total surface area for this type of soot has not been measured, an upper limit of $100 \mathrm{~m}^{2} / \mathrm{g}$ for the BET surface may be assumed in analogy to hexane and decane soot because the used toluene soot was generated under very similar experimental, that is rich combustion conditions (Stadler, 2000; Stadler and Rossi, 2000). Using $\rho=1.8 \mathrm{~g} / \mathrm{cm}^{3}$ as the true density of soot the 10 number of $\mathrm{C}$ atoms per $\mathrm{cm}^{2}$ forming a formal monolayer, $\mathrm{N}_{C}$, may be estimated as $\mathrm{N}_{C}=\left(\left((1.8 / 12) \times 6.023 \times 10^{23}\right)^{2}\right)^{1 / 3}=2.0 \times 10^{15} \mathrm{C}$ atoms $/ \mathrm{cm}^{2}$ for a monolayer. At an estimated BET surface area of $100 \mathrm{~m}^{2} / \mathrm{g}$ or $1000 \mathrm{~cm}^{2} / \mathrm{mg}$ the absolute number of sites $\mathrm{N}_{\text {O3 }}$ (aerosol)/M $\mathrm{M}_{\text {aerosol }}$ obtained from experiment SOOT1 of $2.0 \times 10^{17} \mathrm{sites} / \mathrm{mg}$ leads to $\mathrm{N}_{O 3}($ aerosol $) / \mathrm{S}=2 \times 10^{14}$ sites $\mathrm{cm}^{-2}$ of toluene soot that strongly interact with $\mathrm{O}_{3}$. Con15 sidering the fact that the estimated BET surface most likely represents an upper limit, $\mathrm{N}_{\mathrm{O}_{3}}$ (aerosol)/S approximately corresponds to $10 \%$ or more of a molecular monolayer of carbon atoms on soot. This seems to be a surprisingly large number of reducing sites for a combustion aerosol. Experiment SOOT2 displayed in Table 1 also reveals that there are approximately $\mathrm{N}_{\mathrm{NO} 2}$ (aerosol)/S=1\% of all surface sites on toluene soot that are able to reduce $\mathrm{NO}_{2}$, a number ten times smaller than for $\mathrm{O}_{3}$ which is a stronger oxidizer than $\mathrm{NO}_{2}$. The observed reaction product of the $\mathrm{NO}_{2} /$ soot aerosol interaction is HONO in agreement with results obtained on soot from a rich combustion mixture as reported by Stadler (2000) and Stadler and Rossi (2000). In anticipation of the results to be discussed below, we neither observed uptake of $\mathrm{NO}_{2}$ nor formation of $\mathrm{HONO}$ by probably not responsible for the formation of HONO in the troposphere (Demirdjian and Rossi, 2002). These results are in agreement with those of Bröske et al. (2003).

ACPD

$5,607-654,2005$

A new experimental technique for determining the SOA surface properties

B. Demirdjian and M. J. Rossi

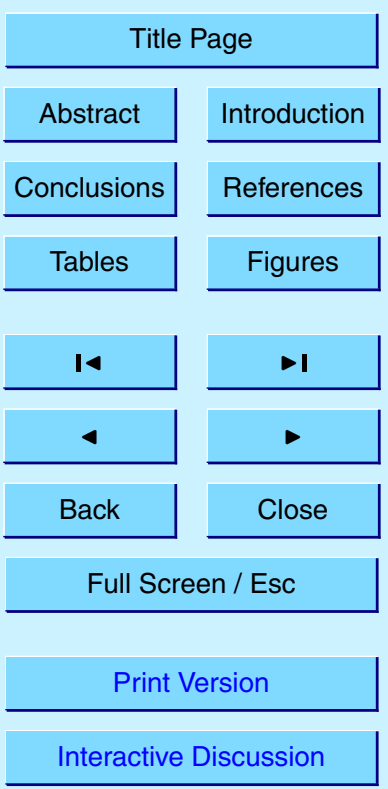


4.5. Evaluation of surface densities of functional groups $\mathrm{N}_{i}$ (aerosol)/S for limonene and toluene aerosols

Considering that SOA had been generated under oxidizing conditions in the presence of $\mathrm{O}_{3}$ at residence times of 1 to $2 \mathrm{~min}$ (Figs. A1 and $\mathrm{A} 2$ ) it is not surprising that no net 5 uptake of both $\mathrm{O}_{3}$ and $\mathrm{NO}_{2}$ could be observed on SOA generated both from limonene and toluene in contrast to toluene soot aerosol. Before evaluating the numbers of basic and carbonyl-containing sites for limonene and toluene SOA per $\mathrm{cm}^{-2}, \mathrm{~N}_{i}($ aerosol)/S, we have to obtain an estimate of the total surface area per mass of $S O A, S / M_{S O A}$, in order to be able to compare the results on SOA with toluene soot.

All titration experiments have been performed on SOA that was generated either from the limonene $/ \mathrm{O}_{3}$ reaction or toluene $/ \mathrm{O}_{3}$ photooxidation at a gas phase residence time $\tau=2 \mathrm{~min}$ and $\mathrm{rh}=90 \%$ which was generally used as displayed in Figs. A1 and $\mathrm{A} 2 \mathrm{~b}$ and led to the aerosol parameters displayed in Tables A1 and A2. For limonene and toluene SOA Figs. A1 and A2b display the most probable mobility diameters of $d=182$ and $250 \mathrm{~nm}$, respectively, at the peak of the PDF. For the sake of simplicity we calculate an effective aerosol diameter $\mathrm{d}_{e f f}$ for the PDF displayed in Figs. A1 and A2b that results in the measured cumulative particle number concentration of $4.5 \times 10^{6}$ and $1.1 \times 10^{6}$ particle $\mathrm{cm}^{-3}$ and the corresponding volume concentration of $1.1 \times 10^{14}$ and $6.7 \times 10^{13} \mathrm{~nm}^{3} / \mathrm{cm}^{3}$ for limonene and toluene SOA, respectively, based on the mobility diameter (Tables A1 and A2). In this way we replace the PDF by one number, namely the effective mobility diameter that defines a monodisperse aerosol with $\mathrm{d}_{e f f}$ equal to 360 and $488 \mathrm{~nm}$ for limonene and toluene SOA, respectively. This will be used from now on in the discussion compared to the most probable aerosol diameter of 182 and $250 \mathrm{~nm}$, respectively, taken from the peak of the PDF (Figs. A1 and A2b). This simplifying assumption avoids the integration procedure that takes into account the detailed form of the PDF.

We are now evaluating the surface area of the SOA per unit mass, $S / M_{S O A}$, in order to normalize the absolute number of surface sites $\mathrm{N}_{i}$ (aerosol) obtained by titra-

A new experimental technique for determining the SOA surface properties

B. Demirdjian and M. J. Rossi

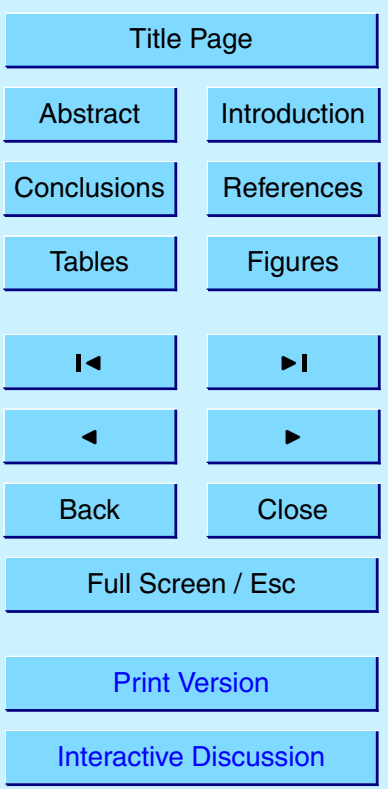


tion. Assuming a density of $1 \mathrm{~g} / \mathrm{cm}^{3}$ as is customary for SOA generated from hydrocarbon oxidation (Rohr et al., 2003; Edney et al., 2000; Bröske et al., 2003) for limonene and toluene SOA the mass and external surface area of a single SOA particle is $2.4 \times 10^{-14}$ and $6.1 \times 10^{-14} \mathrm{~g} /$ particle and $4.1 \times 10^{-9}$ and $7.5 \times 10^{-9} \mathrm{~cm}^{2} /$ particle using 5360 and $488 \mathrm{~nm}$ as effective diameters for limonene and toluene SOA, respectively. Therefore, there are $10^{-3} / 2.4 \times 10^{-14}=4.2 \times 10^{10}$ limonene SOA particles in $1 \mathrm{mg}$ which leads to a surface area $S / M_{S O A}$ of $171 \mathrm{~cm}^{2}$ per $\mathrm{mg}$ of limonene $S O A$ for $\mathrm{d}_{\text {eff }}=360 \mathrm{~nm}$. The corresponding values for toluene SOA are $1.64 \times 10^{10}$ particles per $\mathrm{mg}$ of SOA of unity density leading to $S / M_{S O A}=123 \mathrm{~cm}^{2}$ per $\mathrm{mg}$ of toluene $S O A$ for $\mathrm{d}_{e f f}=488 \mathrm{~nm}$. Table 2 displays numerical values of $\mathrm{N}_{i}($ aerosol)/S for all three types of aerosols studied.

In order to facilitate the comparison between different values of $\mathrm{N}_{i}$ (aerosol) we are expressing it on a relative scale by choosing as a benchmark the number of molecules or atoms (in the case of soot as discussed above) making up a formal molecular monolayer. This was estimated by assuming that the limonene and 5 toluene SOA consisted of a pure liquid droplet of density $\rho=0.841$ and $0.867 \mathrm{~g} / \mathrm{cm}^{3}$ for limonene and toluene, respectively (Weast, 1989). Similar to the estimation of the number $\mathrm{N}_{C}$ of $\mathrm{C}$ atoms on toluene soot presented above we obtain $\mathrm{N}_{\text {/im }}=2.4 \times 10^{14}$ and $\mathrm{N}_{T o l}=3.2 \times 10^{14}$ molecules $\mathrm{cm}^{-2}$ for a formal monolayer of limonene and toluene on the pure liquid. Table 2 displays typical values of fractional monolayers of functional groups probed by the used gas phase molecules on the third line of each entry in per cent of a formal monolayer of the SOA precursor.

The results displayed in Table 2 enable a quantitative comparison of the fractional coverage of a narrow selection of functional groups on different SOA's as well as on toluene soot. Oxidation of the hydrocarbon SOA precursors limonene and toluene

as well as combustion of toluene in a diffusion flame afford the generation of many acidic compounds including mono- and dicarboxylic compounds (Larsen et al., 2001; Liu et al., 2004). Table 2 reveals that 5.0 and $3.4 \%$ of the surface of SOA based on a formal monolayer of its precursor hydrocarbon contain acidic functional groups when the surface is approximated by a pure liquid droplet of the hydrocarbon. The present
5, 607-654, 2005

A new experimental technique for determining the SOA surface properties

B. Demirdjian and M. J. Rossi




technique addresses the surface composition as "seen" from the gas phase and does not allow a conclusion as to the bulk volume concentration of the oxidation products. Trimethylamine is a strong base that should interact even with weakly acidic sites at the SOA interface. However, we can by no means be sure that this number corre5 sponds to a limiting value of acidic sites on the surface of toluene SOA. Toluene soot has a relative surface coverage of $0.2 \%$ regarding surface acidity which is significantly lower than for SOA. However, the normalizing factor $\mathrm{N}_{C}$ (see footnote $\mathrm{c}$ in Table 2) is roughly a factor of ten higher than $\mathrm{N}_{\text {lim }}$ or $\mathrm{N}_{t o l}$ which will lead to lower relative surface coverages. Even so, if one would compare $\mathrm{N}_{\mathrm{NMe} 3}$ (aerosol)/S for toluene soot with ${ }_{10} \mathrm{~N}_{t o l}$ the resulting surface coverage of $1.25 \%$ would still be significantly smaller than for limonene and toluene SOA. Although the absolute number of acidic surface sites per mass on soot is larger by a factor of three or so (Table 2) the surface density is smaller by a factor of three compared to SOA because of the large value of the BET surface of soot compared to SOA which does not have a fractal surface like soot.

Titration with $\mathrm{NH}_{2} \mathrm{OH}$ indicates that SOA particles contain carbonyl groups that may interact with the gas phase. It is well known that SOA contains a plethora of partially oxygenated hydrocarbons, many of which contain carbonyl groups (Larsen et al., 2001). In agreement with this fact our results show a significantly larger surface coverage of carbonyl groups that interact with the gas phase probe $\mathrm{NH}_{2} \mathrm{OH}$ compared to acidic functional groups. Perhaps surprisingly, the value for limonene SOA is a factor of 32 larger than the number of molecules corresponding to a molecular monolayer. This means that some diffusional exchange between the bulk and the surface of a limonene SOA droplet must occur on the time scale of the titration experiment which is in the range of tens of minutes. Some exchange for toluene SOA cannot be excluded either, despite the fact that the surface coverage is less than $100 \%$. Most importantly, the initial rate constant $\mathrm{k}_{\text {uni }}$ for uptake of $\mathrm{NH}_{2} \mathrm{OH}$ corresponds to a $\gamma$ value far from unity which means that the exchange must occur on a time scale significantly longer than $30 \mathrm{~s}$ corresponding to $\mathrm{k}_{e s c}=0.031 \mathrm{~s}^{-1}$. What is important in the present context is that carbonyl groups are apparently available to a large extent for gas phase interaction,
ACPD

$5,607-654,2005$

\section{A new experimental technique for determining the SOA surface properties}

B. Demirdjian and M. J. Rossi

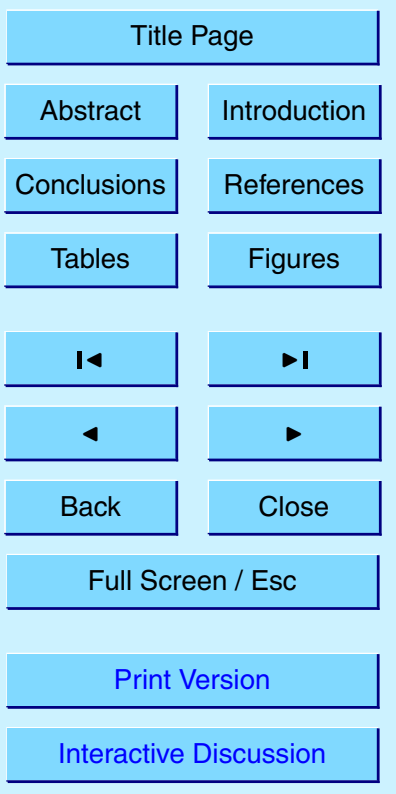


the slow diffusional exchange between bulk and surface notwithstanding. However, the chosen probe $\mathrm{NH}_{2} \mathrm{OH}$ is most likely unable to differentiate between carbonyl groups originating from such disparate molecules as aldehydes, ketones, carbonic acids, esters, anhydrides, amides and others. In contrast, the uptake of $\mathrm{NH}_{2} \mathrm{OH}$ by soot parti5 cles is negligible which is somewhat of a surprise. However, this result may perhaps be an artifact in that the functional groups carrying the surface acidity of soot that is necessary for the oxime formation to occur through general acid catalysis may not be mobile on the soot surface and therefore unable to move, whereas in the presumably liquid limonene and toluene SOA the surface acidity may move to a reaction center 10 where oxime formation with $\mathrm{NH}_{2} \mathrm{OH}$ occurs. As discussed above no oxime formation occurs on a thin film of xanthone in the absence of an acid, in agreement with this proposal. The results for toluene soot with respect to the fractional coverage of reducing or oxidizable sites depends on the strength of the oxidizing power of the probe as has been pointed out above. It seems to be highly variable, at least within a factor of ten, and additional examples will enable the characterization of the soot surface in terms of chemical reactivity in the future.

A close look at typical titration experiments for $\mathrm{N}\left(\mathrm{CH}_{3}\right)_{3}$ in contrast to $\mathrm{NH}_{2} \mathrm{OH}$ probes displayed in Figs. 6 and 7, respectively, reveals that titration is complete for $\mathrm{N}\left(\mathrm{CH}_{3}\right)_{3}$ on toluene SOA and soot aerosol (Fig. 6) as well as for $\mathrm{NH}_{2} \mathrm{OH}$ interacting with toluene

SOA, in contrast to limonene SOA (Fig. 7). In the former case displayed in Fig. 7 the $\mathrm{NH}_{2} \mathrm{OH}$ MS signal at m/e 33 returns to the original MS signal well before the end of the titration reaction at $\mathrm{t}=530 \mathrm{~s}$ (Fig. $7 \mathrm{a}$ ), whereas it has not yet returned to the original level at $\mathrm{t}=1350 \mathrm{~s}$ for the interaction pair $\mathrm{NH}_{2} \mathrm{OH}$ /limonene SOA (Fig. $7 \mathrm{~b}$ ) when the plunger was lowered and exposure of the supported aerosol came to a halt. This may indicate continuing exchange between $\mathrm{NH}_{2} \mathrm{OH}$ and the target carbonyl groups that would take place beyond the actual reaction period which is the reason that only a lower limit for $\mathrm{N}_{\mathrm{NH} 2 \mathrm{OH}}$ (aerosol) may be given at this time (Table 2). In any case, continuing diffusion of carbonyl groups from the bulk towards the aerosol particle surface or diffusion of $\mathrm{NH}_{2} \mathrm{OH}$ into the bulk of the aerosol volume may not be excluded for the case of
ACPD

$5,607-654,2005$

\section{A new experimental technique for determining the SOA surface properties}

B. Demirdjian and

M. J. Rossi

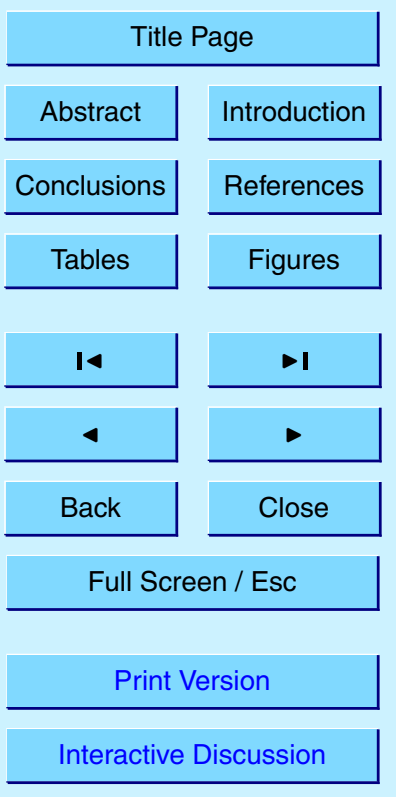


limonene SOA because of the persistence of the titration reaction and our inability to saturate the probe/aerosol reaction system beyond the scheduled end of reaction at $\mathrm{t}=1350 \mathrm{~s}$ (Fig. $7 \mathrm{~b}$ ). The small but measurable continuing reaction rate designates the rate-limiting step which very likely is linked to a diffusional process.

$5 \quad$ Volatile reaction products resulting from the interaction of surface probes have only been detected for soot aerosol. The identity of the products listed in Table 4, HONO (m/e 47) and $\mathrm{O}_{2}$ (m/e 32) has been established using mass spectrometry and is in agreement with previous results (Stadler and Rossi, 2000; Bröske et al., 2003). The salt and oxime reaction products, although not directly observable, are expected to 10 be present at the SOA interface after reaction with $\left(\mathrm{CH}_{3}\right)_{3} \mathrm{~N}$ and $\mathrm{NH}_{2} \mathrm{OH}$, respectively. Water vapor as a product of reaction (4) was not observable either because the $\mathrm{H}_{2} \mathrm{O}$ content of SOA was high according to the MS signal at $\mathrm{m} / \mathrm{e} 18$ thus preventing the observation of small additional amounts of $\mathrm{H}_{2} \mathrm{O}$. It is useful to remember that the formation of SOA examined in the present work generally occurred at elevated relative 15 humidities of $R H \geq 90 \%$ in all our experiments.

\subsection{Uncertainties}

In order to examine the overall uncertainty in the primary parameter of interest, namely $\mathrm{N}_{i}$ (aerosol)/S displayed in Table 2 we will first evaluate the limits of uncertainty in $\mathrm{N}_{i}$ (aerosol) whose absolute value is measured by titration using a specific probe 20 molecule. Figure 6 shows that titration of the acidic surface functional groups using $\mathrm{N}\left(\mathrm{CH}_{3}\right)_{3}$ goes to completion both for toluene soot and SOA in that the MS signal reaches the initial signal level after $150 \mathrm{~s}$. This leads to approximately a $5 \%$ uncertainty in $\mathrm{N}_{\mathrm{N}(\mathrm{CH} 3) 3}$ (aerosol). On the other extreme corresponding to the most unfavorable case, the titration experiments involving $\mathrm{NH}_{2} \mathrm{OH}$ probing the aerosol carbonyl 25 groups of limonene SOA displayed in Fig. 7b show a continuing titration reaction even beyond a duration of $1250 \mathrm{~s}$, which is the time at which the aerosol sample had been isolated from $\mathrm{NH}_{2} \mathrm{OH}$ by lowering the plunger and thus sealing the sample compartment. Judging from the slope of the time-dependent MS signal at $\mathrm{m} / \mathrm{e} 33$ we believe
ACPD

$5,607-654,2005$

\section{A new experimental technique for determining the SOA surface properties}

B. Demirdjian and M. J. Rossi

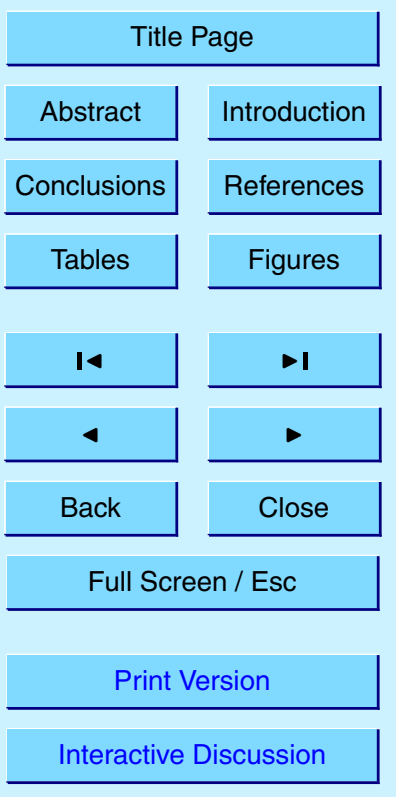


that we underestimate $\mathrm{N}_{\mathrm{NH} 2 \mathrm{OH}}$ (aerosol) by $20 \%$. The case of the $\mathrm{O}_{3}$-titration of oxidizable (reducing) surface functionalities of toluene soot displayed in Fig. 4 should lead to a similar uncertainty of $\mathrm{N}_{\mathrm{O}_{3}}$ (aerosol) of $20 \%$, quite like the case of the $\mathrm{NH}_{2} \mathrm{OH}$ probing the SOA of limonene. Figure 4 shows a significant continuing uptake of $\mathrm{O}_{3}$ even after $51500 \mathrm{~s}$ of titration which indicates that complete saturation of soot by $\mathrm{O}_{3}$ has not yet occurred. As a result $\mathrm{N}_{i}$ (aerosol) is probably underestimated up to $20 \%$ in this case as well.

The uncertainty in $S$ is primarily given by the stability of the PDF of the suspended aerosol that is strongly affected by the duration of the limonene and toluene SOA col10 lection on the Teflon filter. A typical uncertainty is estimated at 5 to $20 \%$ for a collection time of 30 to $120 \mathrm{~min}$, respectively. In conclusion, for both limonene and toluene SOA the combined uncertainty of $\mathrm{N}_{i}($ aerosol)/S may reach values up to $40 \%$. An exception seems to be toluene combustion aerosol where the upper limiting BET surface area has been estimated at $100 \mathrm{~m}^{2} / \mathrm{g}$ in this work. Stadler and Rossi have measured a BET 15 surface area of $70 \mathrm{~m}^{2} / \mathrm{g}$ for decane soot generated under similar rich flame conditions (2000b). If we assign an uncertainty of $\pm 30 \%$ in the BET surface area of toluene soot we arrive at an overall uncertainty of up to $50 \%$ for $\mathrm{N}_{i}$ (soot)/S, a value slightly higher than that for the SOA samples. In conclusion, only additional future work may teach us about realistic uncertainty limits for these experiments because the present levels

\section{Appendix A: Particle Distribution Function (PDF) of limonene, toluene SOA and toluene soot}

Particle size spectra of the aerosol generated from the reaction of $1000 \mathrm{ppm}$ of limonene in the presence of $100 \mathrm{ppm}$ of $\mathrm{O}_{3}$ at $90 \%$ rh at 1 atmosphere of air are dis-

played in Fig. A1 at $10 \mathrm{~min}$ and $1 \mathrm{~h}$ after aerosol particle formation at a gas phase residence time of $\tau=2 \mathrm{~min}$. The mode at $182 \mathrm{~nm}$ is essentially invariant with time despite some minor changes in the particle size distribution in the nucleation mode at aerosol

ACPD

$5,607-654,2005$

A new experimental technique for determining the SOA surface properties

B. Demirdjian and M. J. Rossi

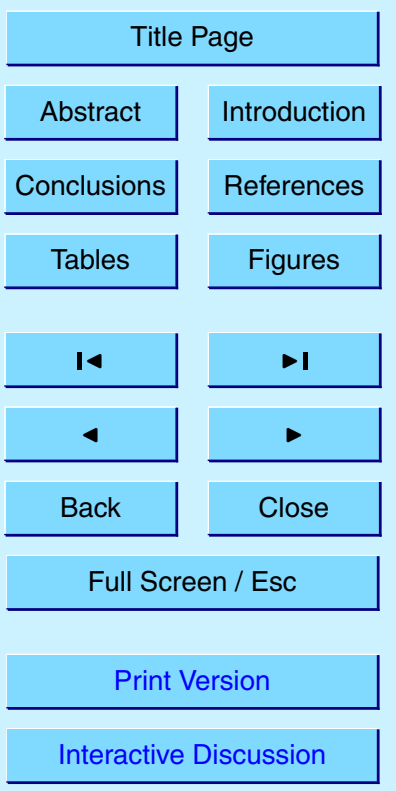


mobility diameters smaller than $40 \mathrm{~nm}$. Table A1 displays the characteristic number, surface and volume concentrations at the two extreme values of rh used, namely dry $(<4 \% \mathrm{rh})$ vs. humid $(90 \% \mathrm{rh})$. It may be concluded that the number, surface and volume concentration of limonene aerosol decreases by a factor of roughly 2.5, 1.7 and

51.6 , respectively, with increasing $\mathrm{rh}$ in contrast to the situation for toluene as discussed below.

Figure A2 displays aerosol particle size distributions of the photochemical production of SOA from toluene using a $\mathrm{Hg} / \mathrm{Xe}$ arc lamp that indicate a dependence on the molecular gas residence time $\tau$ in the aerosol flow reactor. At $\tau=1 \mathrm{~min}$ (Fig. A2a) the 10 size distribution exhibits two modes, located at 60 and $180 \mathrm{~nm}$, whereas it consists of a single peak centered at $230 \pm 20 \mathrm{~nm}$ for $\tau=2 \mathrm{~min}$ (Fig. A2b). Obviously, the SOA concentration in the photochemical reactor is sufficiently large to support particle coagulation processes towards larger mean aerosol particle mobility diameters on an increasing time scale from 1 to $2 \mathrm{~min}$ all the while new gas-to-particle formation processes are 15 taking place simultaneously. In addition, our results also point towards satisfactory stability of the particle size distribution over a typical duration of particle collection on the Teflon membrane filter on the order of an hour or so. These constant experimental conditions throughout the aerosol collection time are necessary in order to enable straightforward interpretation of the properties of a collected macroscopic aerosol filter sample of limonene and toluene SOA.

The particle number concentration for toluene SOA is smaller by roughly a factor of six in going from $\tau=1$ to $2 \mathrm{~min}$ as shown in Table A2. The surface concentration $\left(\mathrm{nm}^{2} / \mathrm{cm}^{3}\right)$ is reduced by approximately a factor of two, whereas the volume concentration $\left(\mathrm{nm}^{3} / \mathrm{cm}^{3}\right)$ is smaller by $30 \%$. The temporal evolution of the metrology of limonene 25 and toluene SOA as displayed in Tables A1 and A2 results in an increase of the mobility diameter accompanied by a decrease of the cumulative number, surface and volume concentrations. This is consistent with continuing oxidation or aging processes during the formation of SOA in the presence of oxidants such as $\mathrm{OH}, \mathrm{O}_{3}$ and $\mathrm{NO}_{3}$ together with on-going adsorptive growth as well as gas-to-particle conversion processes all

\section{A new experimental technique for determining the SOA surface properties}

B. Demirdjian and M. J. Rossi

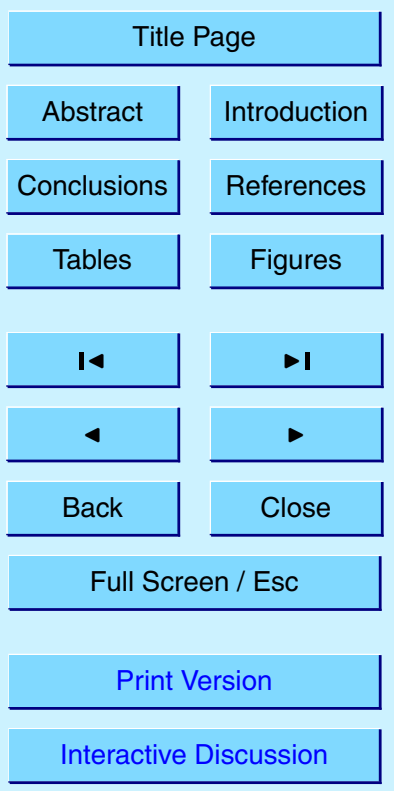


occurring at the same time.

Experiments on toluene $/ \mathrm{O}_{3}$ photooxidation performed under dry conditions, typically at a relative humidity rh of $<4 \%$, showed that the number concentration of particles is reduced by more than a factor of ten (11.3 in Fig. A2c) in contrast to limonene $/ \mathrm{O}_{3}$ 5 SOA that showed a modest increase with increasing $r$ as discussed above. The result for toluene qualitatively confirms that $\mathrm{H}_{2} \mathrm{O}$ vapor plays an important role in SOA formation from toluene $/ \mathrm{O}_{3}$ owing to photooxidation processes supported by $\mathrm{OH}$ free radical. Some of the important reactions are the following:

$\mathrm{O}_{3}+\mathrm{hv} \rightarrow \mathrm{O}_{2}+\mathrm{O}\left({ }^{1} \mathrm{D}\right)$

10

$\mathrm{O}\left({ }^{1} \mathrm{D}\right)+\mathrm{H}_{2} \mathrm{O} \rightarrow 2 \mathrm{OH}$

$\mathrm{OH}+$ toluene $\rightarrow \mathrm{H}_{2} \mathrm{O}+\mathrm{C}_{7} \mathrm{H}_{7}$ (benzyl radical ${ }^{\bullet}$ from $\mathrm{H}$ abstraction)

$\mathrm{OH}+$ toluene $\rightarrow \mathrm{C}_{7} \mathrm{H}_{8} \mathrm{OH}\left(\mathrm{OH}\right.$ addition product $\left.{ }^{\circ}\right)$

Subsequently, the benzyl radicals and/or the $\mathrm{OH}$-addition product to toluene are oxidized further (Atkinson and Arey, 2003). Equations (A1) to (A4) just represent the initiation reactions of toluene photooxidation that are thought to be rate limiting at the very beginning of the SOA formation process.

The role of $\mathrm{H}_{2} \mathrm{O}$ vapor in SOA formation has been investigated thoroughly in recent years using chamber as well as flowing gas experiments (Seinfeld et al., 2001; Edney et al., 2000). The difficulty with these experiments is the fact that one is unable to separate the effect of $\mathrm{H}_{2} \mathrm{O}$ vapor on the SOA formation, that is gas-to-particle conversion processes, from the following adsorptive growth of aerosol particles by adsorption of both organic and $\mathrm{H}_{2} \mathrm{O}$ vapor, notwithstanding the effect of inorganic aerosol components that are not considered here. Despite the complexity of the systems at hand Seinfeld reached the conclusion (Seinfeld et al., 2001) that increasing rh caused modest, albeit monotonic, increases of both the amount of condensed organic mass as well as the amount of condensed $\mathrm{H}_{2} \mathrm{O}$ for five olefin $/ \mathrm{O}_{3}$ systems. However, the yield of SOA

ACPD

$5,607-654,2005$

A new experimental technique for determining the SOA surface properties

B. Demirdjian and M. J. Rossi




varied little with rh in the $\alpha$-pinene/ $\mathrm{O}_{3}$ system (Cocker et al., 2001). On the other hand, Edney et al. (2000) concluded that the variation of the rh did not affect the amount of SOA that formed from the photooxidation of toluene, in distinct contrast to the results ACPD presented here. We therefore conclude that the effect of $\mathrm{H}_{2} \mathrm{O}$ on the formation/growth 5 of SOA is certainly a complex function of experimental parameters such as lifetime $(\tau)$ and its associated time scale for observation, relative humidity ( $\mathrm{rh}$ ), the involved oxidant and precursor concentrations and aging processes, to name just a few.

Finally, control experiments conducted without $\mathrm{O}_{3}$ flow and/or without UV irradiation either led to a negligible or significantly lower particle number concentration $\mathrm{n}$. Briefly, the results may be summarized as follows:

- toluene or limonene vapor, no photons, with or without $\mathrm{H}_{2} \mathrm{O}$ vapor: $\mathrm{n} \cong 10^{1}$ particles $/ \mathrm{cm}^{3}$. This also corresponds to the background count of the (compressed) air used to run the SOA metrology equipment. The various air supplies were filtered across a HEPA filter.

- toluene $+\mathrm{O}_{3}$, no photons, with $\mathrm{H}_{2} \mathrm{O}$ vapor: $\mathrm{n} \cong 10^{4}$ particles $/ \mathrm{cm}^{3}$.

- Standard SOA experiments:

$$
\begin{aligned}
& \text { - toluene }+\mathrm{H}_{2} \mathrm{O}+\mathrm{O}_{3}+\mathrm{hv}: \mathrm{n} \cong 10^{6} \text { particles } / \mathrm{cm}^{3} \\
& \text { - limonene }+\mathrm{H}_{2} \mathrm{O}+\mathrm{O}_{3}: \mathrm{n} \cong 10^{6} \text { particles } / \mathrm{cm}^{3} .
\end{aligned}
$$

These values represent cumulative number concentrations and have been obtained 20 using the additional condensation nuclei counter (CNC, TSI model $3022 \mathrm{~A}$ ) identical to that used in the SMPS system. It was sampling the flow at the same location as the DMA/CNC combination (Fig. 1).

$5,607-654,2005$

A new experimental technique for determining the SOA surface properties

B. Demirdjian and M. J. Rossi

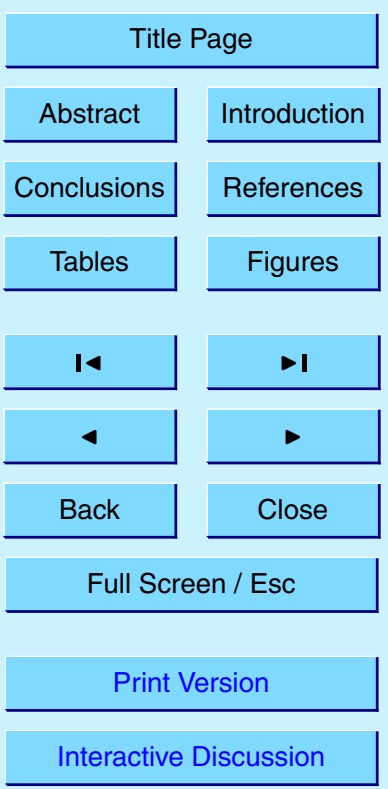


In order to characterize the surface functional groups of filter-deposited SOA we have resorted to FTIR absorption spectroscopy using a photoacoustic cell, a non-destructive and sensitive method that has been designed to preferentially interrogate the gascondensed phase interface (Gosselin et al., 1996). Results displayed in Fig. B1 for filter-supported SOA from both limonene and toluene clearly show the presence of the $\mathrm{O}-\mathrm{H}$ stretching vibration in terms of a strong absorption between 2500 and $3650 \mathrm{~cm}^{-1}$, the asymmetric and symmetric C-H stretching vibration at 2920 and $2850 \mathrm{~cm}^{-1}$, respectively, and the carbonyl $\mathrm{C}=\mathrm{O}$ stretching band at $1720 \mathrm{~cm}^{-1}$. Figure $\mathrm{B} 1$ also shows some signs of hydrocarbon contamination of the filter prior to aerosol deposition (bare Teflon membrane filter). However, both photoacoustic spectra of limonene and toluene SOA, apart from the fact that they differ from each other, have larger signal amplitudes than the control spectrum throughout the IR spectral range of 400 to $4000 \mathrm{~cm}^{-1}$. Qual15 itatively speaking, the photoacoustic spectra of both limonene and toluene SOA show prominent hydroxyl and carbonyl absorptions in addition to complex features in the IR fingerprint region leading to the conclusion that extensive oxidation of the organic phase has occurred. However, the spectral signature of both limonene and toluene SOA is not detailed enough so as to allow major product identification.

20 Acknowledgements. Generous support of Office Fédéral de l'Enseignement et de la Science (OFES) is gratefully acknowledged in the framework of the EU projects NITROCAT and THALOZ.

\section{References}

Allan, J. D., Jimenez, J. L., Williams, P. I., Alfarra, M. R., Bower, K. N., Jayne, J. T., Coe, H., and Worsnop, D. R.: Quantitative sampling using an Aerodyne aerosol mass spectrometer:

A new experimental technique for determining the SOA surface properties

B. Demirdjian and M. J. Rossi

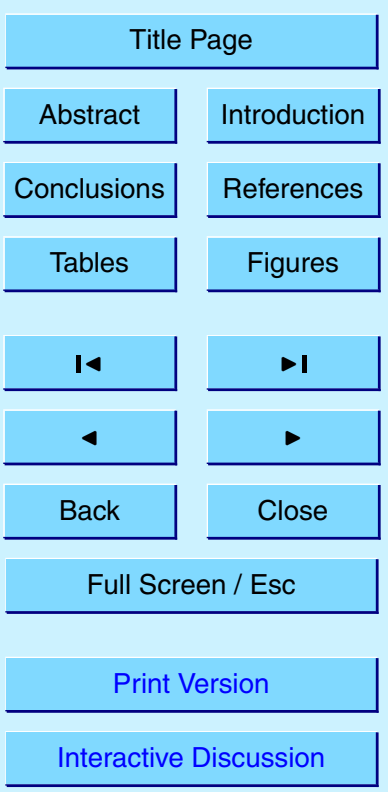


1. Techniques of data interpretation and error analysis, J. Geophys. Res., 108, art. no. 4284, doi:10.1029/2002JD002358, 2003.

Andreae, M. O.: The dark side of aerosols, Nature, 409, 671-672, 2001.

Atkinson, R. and Arey, J.: Atmospheric Degradation of Volatile Organic Compounds, Chem. Rev., 105, 4605-4638, 2003.

Bowman, F. M. and Karamalegos, A. M.: Estimated effects of composition on secondary organic aerosol mass concentrations, Env. Sci. Technol., 36, 2701-2707, 2002.

Bröske, R., Kleffmann, J., and Wiesen, P.: Heterogeneous conversion of $\mathrm{NO}_{2}$ on secondary organic aerosol surfaces: A possible source of nitrous acid (HONO) in the atmosphere?, Atmos. Chem. Phys., 3, 469-474, 2003, SRef-ID: 1680-7324/acp/2003-3-469.

Caloz, F., Fenter, F. F., Tabor, K. D., and Rossi, M. J.: Paper I: Design and construction of a Knudsen-cell reactor for the study of heterogeneous reactions over the temperature range 130-750 K: Performance and limitations, Rev. Sci. Instrum., 68, 3172-3179, 1997.

15 Charlson, R. J., Seinfeld, J. H., Nenes, A., Kulmala, M., Laaksonen, A., and Facchini, M. C.: Atmospheric science - Reshaping the theory of cloud formation, Science, 292, 2025-2026, 2001.

Cocker, D. R., Clegg, S. L., Flagan, R. C., and Seinfeld, J. H.: The effect of water on gas-particle partitioning of secondary organic aerosol, Part I: $\alpha$-pinene/ozone system, Atmos. Environ., $20 \quad 35,6049-6072,2001$.

Cruz, C. N. and Pandis, S. N.: The effect of organic coatings on the cloud condensation nuclei activation of inorganic atmospheric aerosol, J. Geophys. Res., 103, 13111-13123, 1998.

Decesari, S., Facchini, M. C., Mircea, M., Cavalli, F., and Fuzzi, S.: Solubility properties of surfactants in atmospheric aerosol and cloud/fog water samples, J. Geophys. Res., 108, art. no. 4685, doi:10.1029/2003JD003566, 2003.

Demirdjian, B. and Rossi, M. J.: Chemical reactivity of soot and secondary organic aerosols generated under laboratory conditions, Proceedings of the 6th International ETH Conference on Nanoparticle Measurement, 19-21 August 2002, Zurich, Switzerland, 2002.

Edney, E. O., Driscoll, D. J., Speer, R. E., Weathers, W. S., Kleindienst, T. E., Li, W., and Smith, D. F.: Impact of aerosol liquid water on secondary organic aerosol yields of irradiated toluene/propylene/ $\mathrm{NO}_{x} /\left(\mathrm{NH}_{4}\right)_{2} \mathrm{SO}_{4}$ /air mixtures, Atmos. Environ., 34, 3907-3919, 2000.

Ellison, G. B., Tuck, A. F., and Vaida, V.: Atmospheric processing of organic aerosols, J. Geophys. Res., 104, 11633-11641, 1999.

ACPD

$5,607-654,2005$

\section{A new experimental technique for \\ determining the SOA surface properties}
B. Demirdjian and

M. J. Rossi

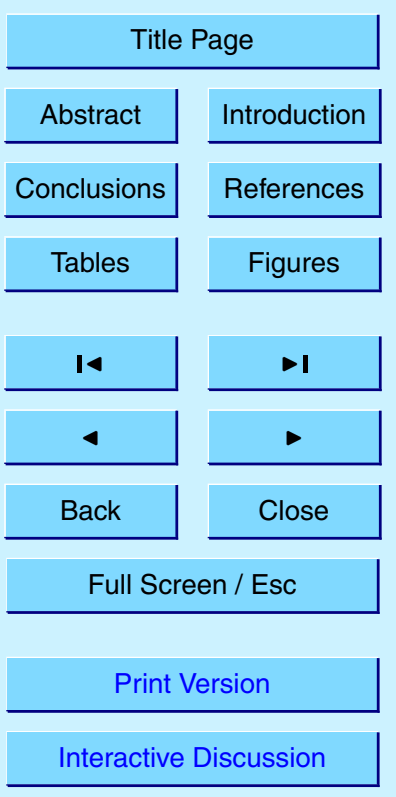


Facchini, M. C., Fuzzi, S., Zappoli, S., Andracchio, A., Gelencser, A., Kiss, G., Krivacsy, Z., Meszaros, E., Hansson, H. C., Alsberg, T., and Zebuhr, Y.: Partitioning of the organic aerosol component between fog droplets and interstitial air, J. Geophys. Res., 104, 26 821-26832, 1999a.

5 Facchini, M. C., Mircea, M., Fuzzi, S., and Charlson, R. J.: Cloud albedo enhancement by surface-active organic solutes in growing droplets, Nature, 401, 257-259, $1999 \mathrm{~b}$.

Finlayson-Pitts, B. J. and Pitts Jr., J. N.: Chemistry of the Upper and Lower Atmosphere, Theory, Experiments and Applications, Academic Press, 2000.

Gosselin, F., Di Renzo, D., Ellis, T. H., and Lubell, W. D.: Photoacoustic FTIR spectroscopy, a nondestructive method for sensitive analysis of solid-phase organic chemistry, J. Org. Chem., 61, 7980-7981, 1996.

Griffin, R. J., Cocker III, D. R., Seinfeld, J. H., and Dabdub, D.: Estimate of global atmospheric organic aerosol from oxidation of biogenic hydrocarbons, Geophys. Res. Lett., 26, 27212724, 1999.

Haywood, J. M. and Boucher, O.: Estimates of the direct and indirect radiative forcing due to tropospheric aerosols: A review, Rev. Geophys., 38, 513-543, 2000.

Jacobson, M. Z., Hansson, H. C., Noone, K. J., and Charlson, R. J.: Organic atmospheric aerosols: Review and state of the science, Rev. Geophys., 38, 267-294, 2000.

Janson, R., Rosman, K., Karlsson, A., and Hansson, H. C.: Biogenic emissions and gaseous precursors to forest aerosols, Tellus B, 53, 423-440, 2001.

Jeffries, H. E.: Photochemical Air Pollution, in: Composition, Chemistry, and Climate of the Atmosphere, edited by: Singh, H. B., Van Nostrand Reinhold New York, 1995.

Künzli, N., Kaiser, R., Medina, S., Studnicka, M., Chanel, O., Filliger, P., Herry, M., Horak, F., Puybonnieux-Texier, V., Quenel, P., Schneider, J., Seethaler, R., Vergnaud J. C., and Sommer, H.: Public-health impact of outdoor and traffic-related air pollution: A European Assessment, Lancet, 356, 795-801, 2000.

Larsen, B. R., Di Bella, D., Glasius, M., Winterhalter, R., Jensen, N. R., and Hjorth, J.: Gas Phase OH Oxidation of Monoterpenes: Gaseous and Particulate Products, J. Atmos. Chem., 38, 231-276, 2001.

30 Liu, X., Mason, M., Krebs, K., and Sparks, L.: Full Scale Chamber Investigation and Simulation of Air Freshener Emissions in the Presence of Ozone, Env. Sci. Technol., 38, 2802-2812, 2004.

Middlebrook, A. M., Murphy, D. M., and Thomson, D. S.: Observations of organic material in in-

ACPD

$5,607-654,2005$

\section{A new experimental technique for \\ determining the SOA surface properties}

B. Demirdjian and

M. J. Rossi

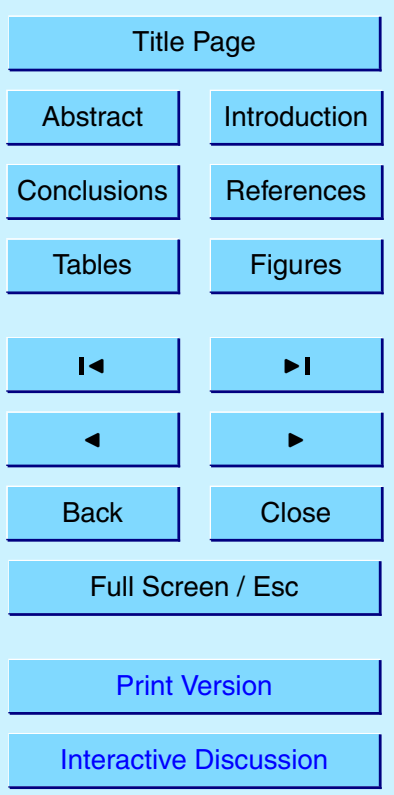


dividual marine particles at Cape Grim during the First Aerosol Characterization Experiment (ACE 1), J. Geophys. Res., 103, 16 475-16 483, 1998.

Noble, C. A. and Prather, K. A.: Real-time single particle mass spectrometry: A historical review of a quarter century of the chemical analysis of aerosols, Mass. Spectrom. Rev., 19, 248-274, 2000.

Novakov, T. and Corrigan, C. E.: Cloud condensation nucleus activity of the organic component of biomass smoke particles, Geophys. Res. Lett., 23, 2141-2144, 1996.

Novakov, T., Hegg, D. A., and Hobbs, P. V.: Airborne measurements of carbonaceous aerosols on the East Coast of the United States, J. Geophys. Res., 102, 30 023-30 030, 1997.

O'Dowd, C. D., Jimenez, J. L., Bahreini, L., Flagan, R. C., Seinfeld, J. H., Hameri, K., Kulmala, M., and Hoffmann, T.: Marine aerosol formation from biogenic iodine emissions, Nature, 417, 632-636, 2002a.

O'Dowd, C. D., Aalto, P., Hameri, K., Kulmala, M., and Hoffmann, T.: Aerosol formation Atmospheric particles from organic vapours, Nature, 416, 497-498, 2002b.

15 Odum, J. R., Jungkamp, T. P. W., Griffin, R. J., Flagan, R. C., and Seinfeld, J. H.: The Atmospheric Aerosol-Forming Potential of Whole Gasoline Vapor, Science, 276, 96-99, 1997.

Pankow, J. F.: Further discussion of the octanol/air partition coefficient $\mathrm{K}_{o a}$ as a correlating parameter for gas/particle partitioning coefficients, Atmos. Environ., 32, 1493-1497, 1998.

Posfai, M., Xu, H., Anderson, J. R., and Buseck, P.: Wet and dry sizes of atmospheric aerosol particles: An AFM - TEM study, Geophys. Res. Lett., 25, 1907-1910, 1998.

Ramanathan, V., Crutzen, P. J., Kiehl, J. T., and Rosenfeld, D.: Atmosphere - Aerosols, climate, and the hydrological cycle, Science, 294, 2119-2124, 2001.

Ramaswamy, V., Boucher, O., Haigh, J., Hauglustaine, D., Haywood, J. M., Myhre, G., Nakajima, T., Shi, G. Y., and Solomon, S.: Radiative Forcing of Climate Change, Climate Change 2001: The Scientific Basis, Contribution of Working Group I to the Third Assessment Report of the Intergovernmental Panel on Climate Change, edited by: Houghton, J. N., Ding, Y., Griggs, D. J., Noguer, M., Linden, P. v. d., Dai, X., and Maskell, K., Cambridge University Press, 2001.

Ravishankara, A. R.: Heterogeneous and multiphase chemistry in the troposphere, Science, $30 \quad$ 276, 1058-1065, 1997.

Rogge, W. F., Mazurek, M. A., Hildemann, L. M., Cass, G. R., and Simoneit, B. R. T.: Quantification of urban organic aerosols at a molecular level - Identification, abundance and seasonal variation, Atmos. Environ., 27, 1309-1330, 1993.

\section{ACPD}

$5,607-654,2005$

\section{A new experimental technique for \\ determining the SOA surface properties}

B. Demirdjian and

M. J. Rossi

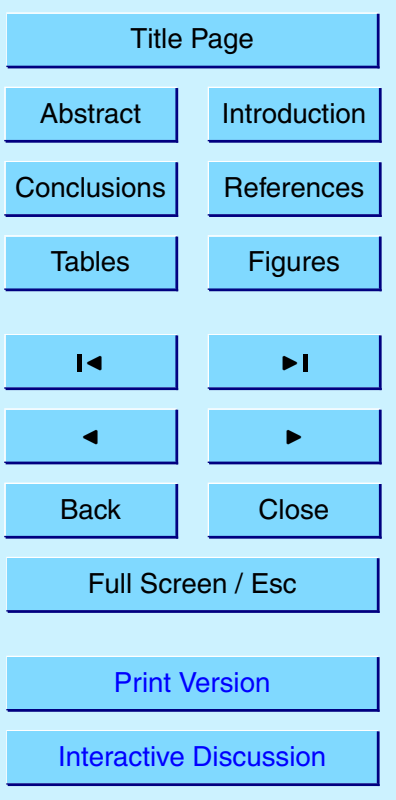


Rohr, A. C., Weschler, C. J., Koutrakis, P., and Spengler, J. D.: Generation and quantification of ultrafine particles through terpene/ozone reaction in a chamber setting, Aerosol Sci. Technol., 37, 65-78, 2003.

Rudich, Y.: Laboratory Perspectives on the Chemical Transformations of Organic matter in Atmospheric Particles, Chem. Rev., 103, 5097-5124, 2003.

Saxena, P., Hildemann, L. M., McMurry, P. H., and Seinfeld, J. H.: Organics alter hygroscopic behavior of atmospheric particles, J. Geophys. Res., 100, 18755-18770, 1995.

Schenk, P. W.: Handbook of preparative Inorganic Chemistry, 2nd edition, Vol. I, edited by: Brauer, G., Academic Press, New York, 500, 1963.

10 Seinfeld, J. H. and Pandis, S. N.: Atmospheric Chemistry and Physics: From Air Pollution to Climate Change, John Wiley \& Sons, New York, 1998.

Seinfeld, J. H., Erdakos, G. B., Asher, W. E., and Pankow, J. F.: Modeling the Formation of Secondary Organic Aerosol (SOA), 2. The Predicted Effects of Relative Humidity on Aerosol Formation in the $\alpha$-Pinene-, $\beta$-Pinene-, Sabinene-, $\Delta^{3}$-Carene-, and Cyclohexene-Ozone 15 Systems, Env. Sci. Technol., 35, 1806-1817, 2001.

Smith, J. N., Moore, K. F., McMurry, P. H., and Eisele, F. L.: Atmospheric measurements of sub-20 nm diameter particle chemical composition by thermal desorption chemical ionization mass spectrometry, Aerosol Sci. Technol., 38, 100-110, 2004.

Stadler, D.: A Laboratory Study of Heterogeneous Reactions relevant to the Atmospheric

20 Boundary Layer: Soot as a reactive Substrate, Thesis no. 2258, Ecole Polytechnique Fédérale de Lausanne (EPFL), 2000.

Stadler, D. and Rossi, M. J.: The reactivity of $\mathrm{NO}_{2}$ and $\mathrm{HONO}$ on flame soot at ambient temperature: The influence of combustion conditions, Phys. Chem. Chem. Phys., 2, 5420-5429, 2000.

25 Thomas, G. E., Olivero, J. J., Jensen, E. J., Schröder, W., and Toon, O. W.: Relation between increasing methane and the presence of ice clouds at the mesopause, Nature, 338, 490492, 1989.

Tobias, H. J. and Ziemann, P.: Thermal desorption mass spectrometric analysis of organic aerosol formed from reactions of 1-tetradecene and $\mathrm{O}_{3}$ in the presence of alcohols and

$30 \quad$ carboxylic acids, J. Env. Sci. Technol., 34, 2105-2115, 2000.

Weast, R. C.: CRC Handbook of Chemistry and Physics, 70th Edition (1989-1990), CRC Press, Inc., Boca Raton, Fla., 1989.

Williams, D. H. and Fleming, I.: Spektroskopische Methoden in der organischen Chemie, Georg

ACPD

5, 607-654, 2005

\section{A new experimental technique for determining the SOA surface properties}

B. Demirdjian and

M. J. Rossi

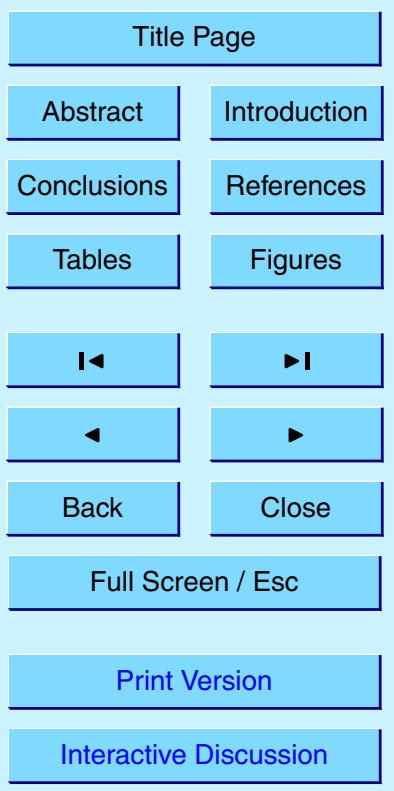


Thieme Verlag Stuttgart, 2. Auflage, Tabelle 3-11, 1971.

Zhang, Q., Stanier, C. O., Canagaratna, M. R., Jayne, J. T., Worsnop, D. R., Pandis, S. N., and Jimenez, J. L.: Insights into the Chemistry of New Particle Formation and Growth Events in Pittsburgh based on Aerosol Mass Spectrometry, Env. Sci. Technol., 38, 4797-4809, 2004.

\section{ACPD}

$5,607-654,2005$

\section{A new experimental technique for determining the SOA surface properties}

B. Demirdjian and M. J. Rossi

Title Page

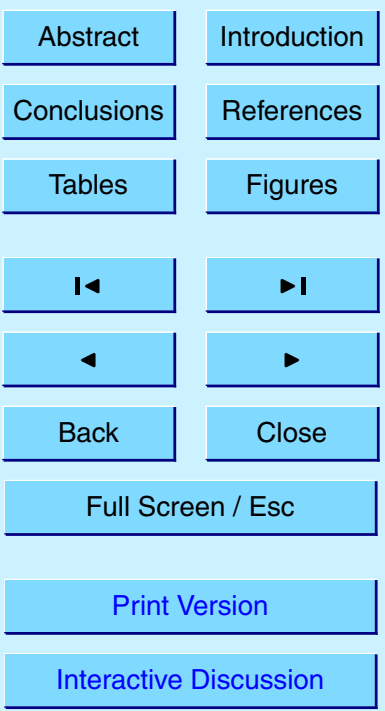




\section{ACPD}

Table 1. Typical results of aerosol surface characterization experiments using molecular $5,607-654,2005$ probes.

\begin{tabular}{|c|c|c|c|c|c|c|c|c|}
\hline $\begin{array}{l}\text { SOA } \\
\text { (VOC) }\end{array}$ & $\begin{array}{l}\operatorname{VOC}^{a} \text { flow } \\
(\mathrm{ml} / \mathrm{min})\end{array}$ & $\mathrm{H}_{2} \mathrm{O}^{b}$ & $\begin{array}{l}\Delta_{m / e}^{c} \\
(\%)\end{array}$ & $\begin{array}{l}\text { SOA (soot) mass } \\
\left(\mathrm{M}_{\mathrm{SOA}} / \mathrm{mg}\right)\end{array}$ & $\begin{array}{l}\text { average rate } \\
(\mathrm{mg} / \mathrm{h})\end{array}$ & $\begin{array}{l}\text { probe } \\
\text { molecule }\end{array}$ & $\begin{array}{l}\left(\mathrm{N}_{i} / \mathrm{M}_{S O A}\right)^{d} \\
(\mathrm{molec} / \mathrm{mg})\end{array}$ & $\mathrm{k}_{\text {uni }} / \mathrm{k}_{e s c}$ \\
\hline LIM 1 & 10 & no & - & 3.7 & - & & & \\
\hline LIM 2 & 10 & yes & - & 3.1 & - & & & \\
\hline LIM 3 & 10 & no & 72 & 2.9 & 3.43 & & & \\
\hline LIM 4 & 10 & no & - & 1.3 & - & $\left(\mathrm{CH}_{3}\right)_{3} \mathrm{~N}$ & $1.9510^{15}$ & 0.096 \\
\hline LIM 5 & 10 & no & 90 & 3.4 & 2.92 & $\left(\mathrm{CH}_{3}\right)_{3} \mathrm{~N}$ & $2.0910^{15}$ & 0.138 \\
\hline LIM 6 & 10 & yes & - & 6.0 & - & $\left(\mathrm{CH}_{3}\right)_{3} \mathrm{~N}$ & $2.1310^{15}$ & 0.254 \\
\hline LIM 7 & 10 & no & 83 & 5.2 & 3.46 & $\mathrm{O}_{3}$ & & \\
\hline LIM 8 & 10 & yes & 97 & 4.3 & - & - & & \\
\hline LIM 9 & 10 & yes & - & 2.2 & - & $\mathrm{NH}_{2} \mathrm{OH}$ & $1.3710^{18}$ & 1.04 \\
\hline LIM 10 & 10 & yes & - & 1.2 & - & $\mathrm{NH}_{2} \mathrm{OH}$ & $1.3110^{18}$ & 0.68 \\
\hline TOL 1 & 2 & yes & 45 & 4.9 & 1.88 & $\left(\mathrm{CH}_{3}\right)_{3} \mathrm{~N}$ & $1.2610^{15}$ & 0.138 \\
\hline TOL 2 & 2 & yes & 31 & 4.5 & 1.82 & $\mathrm{O}_{3}$ & & \\
\hline TOL 3 & 2 & yes & 36 & 4.2 & 2.29 & $\mathrm{NO}_{2}$ & & \\
\hline TOL 4 & 2 & yes & 19 & 0.8 & - & $\left(\mathrm{CH}_{3}\right)_{3} \mathrm{~N}$ & $1.3910^{15}$ & 0.082 \\
\hline TOL 5 & 2 & yes & - & 0.8 & - & $\mathrm{NH}_{2} \mathrm{OH}$ & - & \\
\hline TOL 6 & 2 & yes & - & 1.2 & - & $\mathrm{NH}_{2} \mathrm{OH}$ & $9.2510^{15}$ & \\
\hline SOOT $1^{e}$ & - & - & - & 2.1 & - & $\mathrm{O}_{3}$ & $2.0210^{17}$ & \\
\hline SOOT $2^{e}$ & - & - & - & 1.3 & - & $\mathrm{NO}_{2}$ & $1.8110^{16}$ & \\
\hline SOOT $3^{e}$ & - & - & - & 2.0 & - & $\left(\mathrm{CH}_{3}\right)_{3} \mathrm{~N}$ & $4.0310^{15}$ & \\
\hline
\end{tabular}

\section{A new experimental technique for determining the SOA surface properties}

B. Demirdjian and

M. J. Rossi

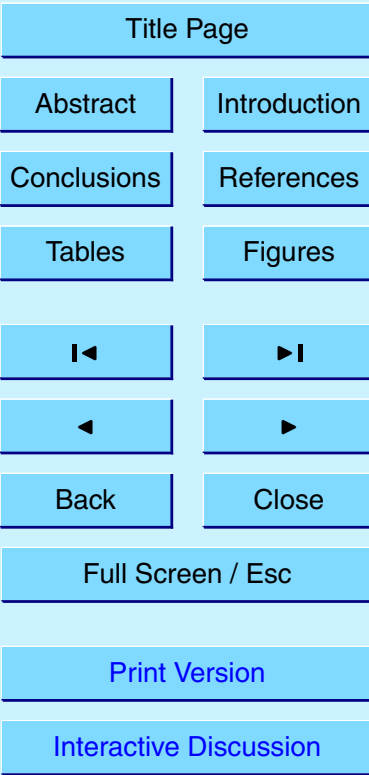

${ }^{a}$ the concentration of the SOA precursor hydrocarbon (limonene, toluene) is $1000 \pm 150 \mathrm{ppm}$ at $296 \pm 2 \mathrm{~K}$.

$b$ "no" corresponds to $\mathrm{rh}<4 \%$, "yes" to $90 \pm 5 \%$ rh.

${ }^{c}$ based on the $\mathrm{m} / \mathrm{e} 68$ fragment ion $\left(\mathrm{C}_{5} \mathrm{H}_{8}^{+}\right)$and 92 molecular ion $\left(\mathrm{C}_{7} \mathrm{H}_{8}^{+}\right)$for limonene and toluene, respectively.

${ }^{d}$ number of probe molecules lost from the gas phase per mg of SOA owing to heterogeneous reaction.

${ }^{e}$ combustion aerosol from toluene diffusion flame. 
Table 2. Summary of titration experiments at $296 \pm 2 \mathrm{~K}$ : nature and number of substrate functional groups on the surface of SOA of limonene and toluene at $90 \% \mathrm{rh}$ and $\tau=2 \mathrm{~min}$ as well as on toluene soot. Bracketed products denote non-volatile compounds that are not observable in the gas phase using MS.

\begin{tabular}{|c|c|c|c|c|c|c|c|c|}
\hline & \multicolumn{2}{|l|}{$\mathrm{O}_{3}$} & \multicolumn{2}{|l|}{$\mathrm{NO}_{2}$} & \multicolumn{2}{|c|}{$\left(\mathrm{CH}_{3}\right)_{3} \mathrm{~N}$} & \multicolumn{2}{|l|}{$\mathrm{NH}_{2} \mathrm{OH}$} \\
\hline & $\begin{array}{c}\mathrm{N}_{O 3} / \mathrm{M}_{S O A}^{d} \\
\mathrm{~N}_{O 3} / \mathrm{S}^{e} \\
\mathrm{ML}(\%)^{f}\end{array}$ & product & $\begin{array}{c}\mathrm{N}_{\mathrm{NO} 2} / \mathrm{M}_{S O A}^{d} \\
\mathrm{~N}_{\mathrm{NO} 2} / \mathrm{S}^{e} \\
\mathrm{ML}(\%)^{f}\end{array}$ & product & $\begin{array}{c}\mathrm{N}_{N M e 3} / \mathrm{M}_{S O A}^{d} \\
\mathrm{~N}_{N M e 3} / \mathrm{S}^{e} \\
\mathrm{ML}(\%)^{f}\end{array}$ & product & $\begin{array}{c}\mathrm{N}_{N H 2 O H} / \mathrm{M}_{S O A}^{d} \\
\mathrm{~N}_{N H 2 O H} / \mathrm{S}^{e} \\
\mathrm{ML}(\%)^{f}\end{array}$ & product \\
\hline $\begin{array}{l}\text { limonene } \\
\mathrm{SOA}^{a}\end{array}$ & no reactivity & & no reactivity & & $\begin{array}{c}(2.1 \pm 0.1) \times 10^{15} \\
(1.2 \pm 0.1) \times 10^{13} \\
5.0\end{array}$ & (salt) & $\begin{array}{c}>(1.3 \pm 0.1) \times 10^{18} \\
>(7.6 \pm 0.1) \times 10^{15} \\
\quad>\times 31.7^{g}\end{array}$ & (oxime) \\
\hline $\begin{array}{l}\text { toluene } \\
\operatorname{SOA}^{b}\end{array}$ & no reactivity & - & no reactivity & - & $\begin{array}{c}(1.3 \pm 0.2) \times 10^{15} \\
(1.1 \pm 0.2) \times 10^{13} \\
3.4\end{array}$ & (salt) & $\begin{array}{c}(9.3 \pm 0.3) \times 10^{15} \\
(7.6 \pm 0.2) \times 10^{13} \\
23.7\end{array}$ & (oxime) \\
\hline $\begin{array}{l}\text { toluene } \\
\text { soot }^{c}\end{array}$ & $\begin{array}{c}(2.0 \pm 0.2) \times 10^{17} \\
(2.0 \pm 0.2) \times 10^{14} \\
10.0\end{array}$ & $\mathrm{O}_{2}$ & $\begin{array}{c}(1.8 \pm 0.2) \times 10^{16} \\
(1.8 \pm 0.2) \times 10^{13} \\
0.90\end{array}$ & HONO & $\begin{array}{c}(4.0 \pm 0.2) \times 10^{15} \\
(4.0 \pm 0.2) \times 10^{12} \\
0.20\end{array}$ & (salt) & no reactivity & - \\
\hline
\end{tabular}

${ }^{a} \mathrm{~S}=171 \mathrm{~cm}^{2} / \mathrm{mg}, \mathrm{N}_{\text {lim }}=2.4 \times 10^{14}$ molecule $\mathrm{cm}^{-2}$ per monolayer (ML).

${ }^{b} \mathrm{~S}=123 \mathrm{~cm}^{2} / \mathrm{mg}, \mathrm{N}_{t o l}=3.2 \times 10^{14}$ molecule $\mathrm{cm}^{-2}$ per ML.

${ }^{c} \mathrm{~S}=10^{3} \mathrm{~cm}^{2} / \mathrm{mg}, \mathrm{N}_{C}=2.0 \times 10^{15}$ molecule $\mathrm{cm}^{-2}$ per $\mathrm{ML}$.

${ }^{d}$ Units of molecule/mg.

${ }^{e}$ Units of molecule $/ \mathrm{cm}^{2}$.

${ }^{f}$ Fractional surface coverage in \% of functional groups on SOA or soot.

$g$ This number corresponds to a factor of 31.7 times the surface coverage based on the assumption that limonene forms a formal molecular monolayer.

\section{A new experimental technique for determining the SOA surface properties}

B. Demirdjian and

M. J. Rossi

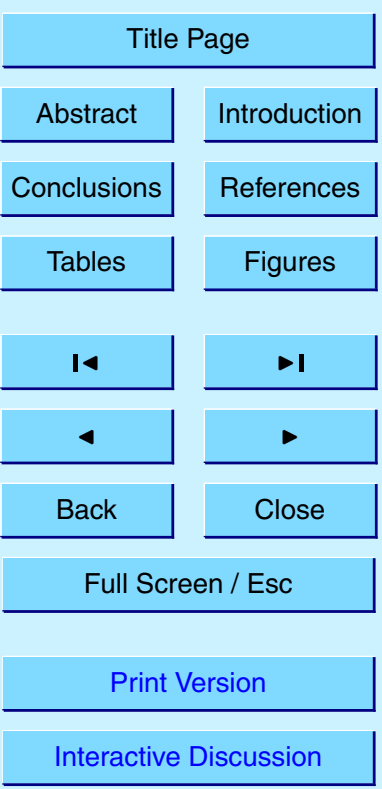




\section{ACPD}

$5,607-654,2005$

\section{A new experimental technique for determining the SOA surface properties}

B. Demirdjian and M. J. Rossi

Table A1. Particle size distribution function for limonene $/ \mathrm{O}_{3}$ aerosol at $\tau=2 \mathrm{~min}$ and $296 \pm 2 \mathrm{~K}$.

\begin{tabular}{ccccc}
\hline $\begin{array}{c}\text { relative humidity } \\
(\%)\end{array}$ & $\begin{array}{c}\text { number concentration } \\
\left(\text { particles } / \mathrm{cm}^{3}\right)\end{array}$ & $\begin{array}{c}\text { Surface concentration } \\
\left(\mathrm{nm}^{2} / \mathrm{cm}^{3}\right)\end{array}$ & $\begin{array}{c}\text { volume concentration } \\
\left(\mathrm{nm}^{3} / \mathrm{cm}^{3}\right)\end{array}$ & $\begin{array}{c}\text { aerosol mode } \\
(\mathrm{nm})\end{array}$ \\
\hline Dry $(<4 \%)$ & $1.110^{7}$ & $2.410^{12}$ & $1.710^{14}$ & 150 \\
$\cong 90 \%$ & $4.510^{6}$ & $1.410^{12}$ & $1.110^{14}$ & 182 \\
\hline
\end{tabular}

Title Page

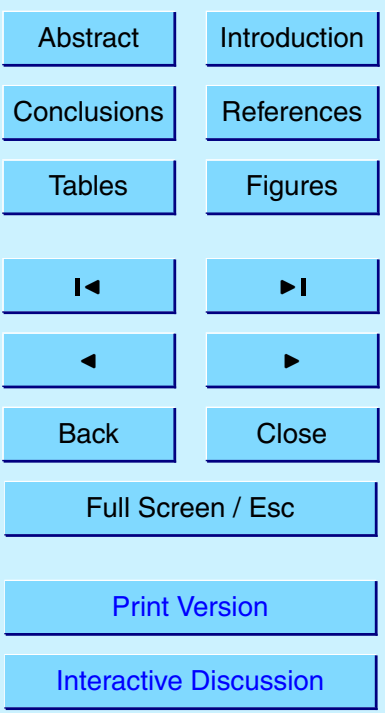




\section{ACPD}

$5,607-654,2005$

\section{A new experimental technique for determining the SOA surface properties}

B. Demirdjian and M. J. Rossi

Table A2. Particle size distribution function for SOA generated from the photooxidation of toluene $/ \mathrm{O}_{3}$ at $296 \pm 2 \mathrm{~K}$ and $\mathrm{rh}=90 \%$ using a $150 \mathrm{~W} \mathrm{Hg} / \mathrm{Xe}$ arc lamp.

\begin{tabular}{ccccc}
\hline $\begin{array}{c}\text { Gas residence } \\
\text { time } \tau(\mathrm{min})\end{array}$ & $\begin{array}{c}\text { number concentration } \\
\text { particles } / \mathrm{cm}^{3}\end{array}$ & $\begin{array}{c}\text { surface concentration } \\
\mathrm{nm}^{2} / \mathrm{cm}^{3}\end{array}$ & $\begin{array}{c}\text { volume concentration } \\
\mathrm{nm}^{3} / \mathrm{cm}^{3}\end{array}$ & $\begin{array}{c}\text { aerosol mode } \\
(\mathrm{nm})\end{array}$ \\
\hline 1 & $6.3 \times 10^{6}$ & $1.3 \times 10^{12}$ & $9.8 \times 10^{13}$ & $60 / 180$ \\
2 & $1.1 \times 10^{6}$ & $7.0 \times 10^{11}$ & $6.7 \times 10^{13}$ & $230 \pm 20$ \\
\hline
\end{tabular}

\section{Title Page}

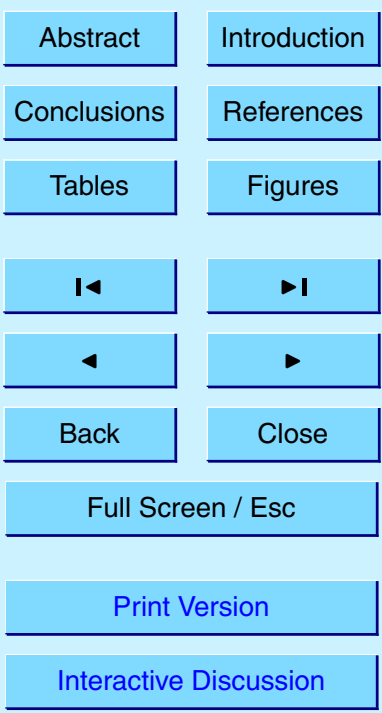




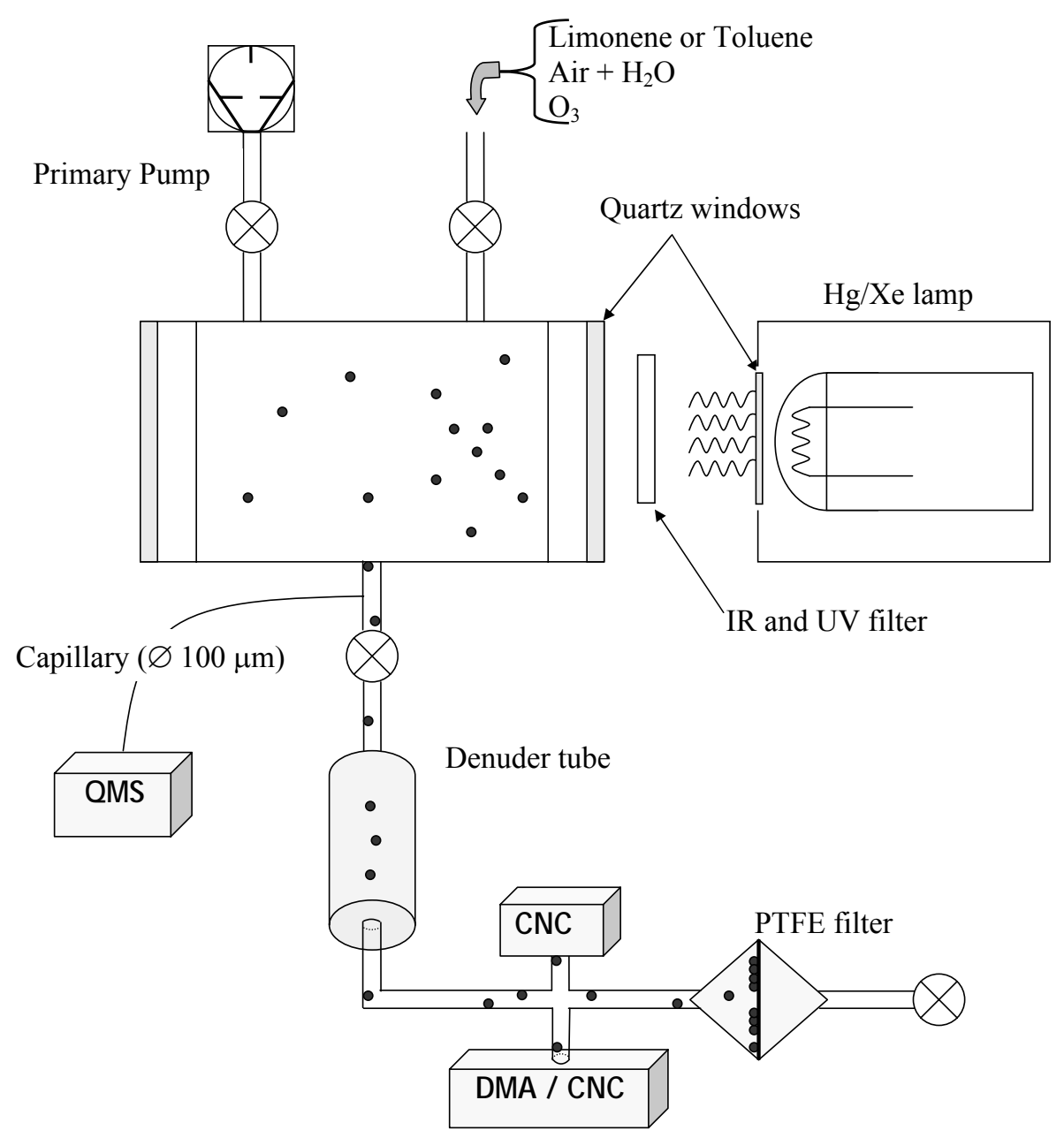

ACPD

$5,607-654,2005$

A new experimental technique for determining the SOA surface properties

B. Demirdjian and M. J. Rossi

\section{Title Page}

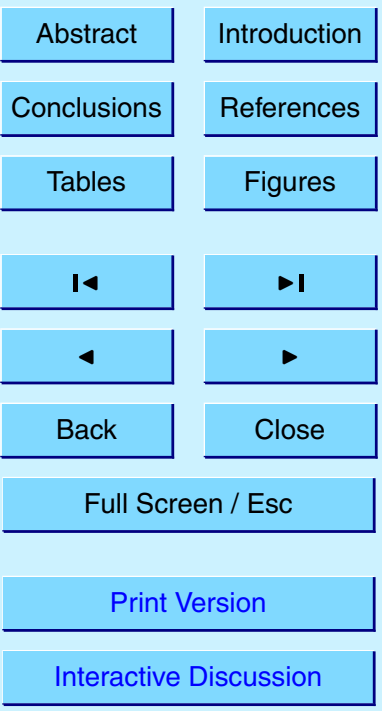

Fig. 1. Experimental apparatus for the production and characterization of SOA. 


\section{ACPD}

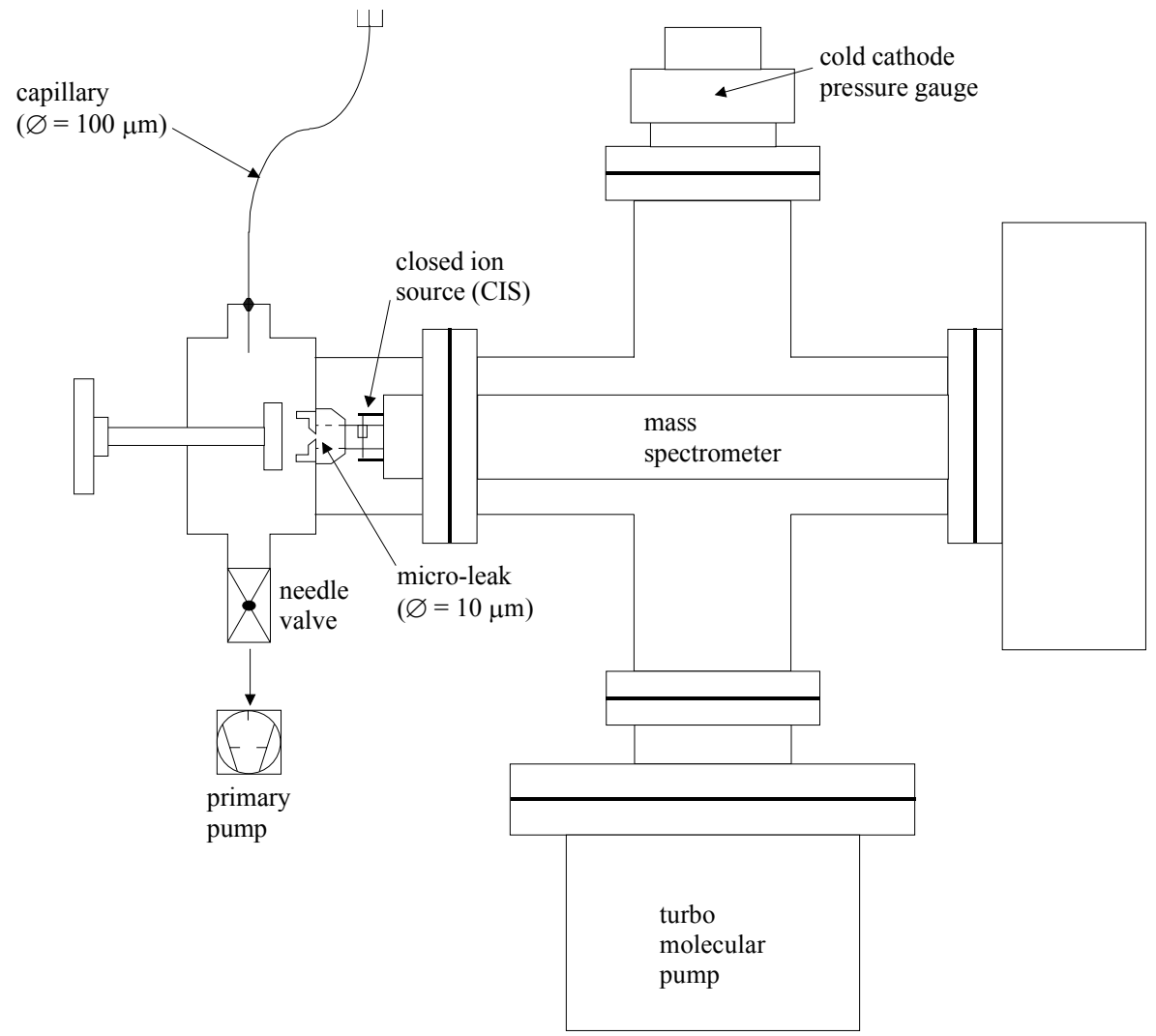

$5,607-654,2005$

A new experimental technique for determining the SOA surface properties

B. Demirdjian and M. J. Rossi

Title Page

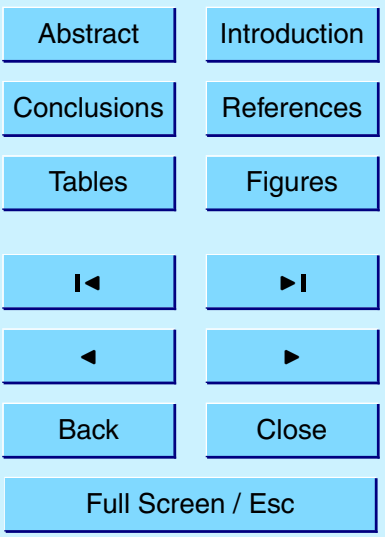

Fig. 2. Description of the detection chamber equipped with a differentially pumped mass spectrometer.

Print Version

Interactive Discussion 

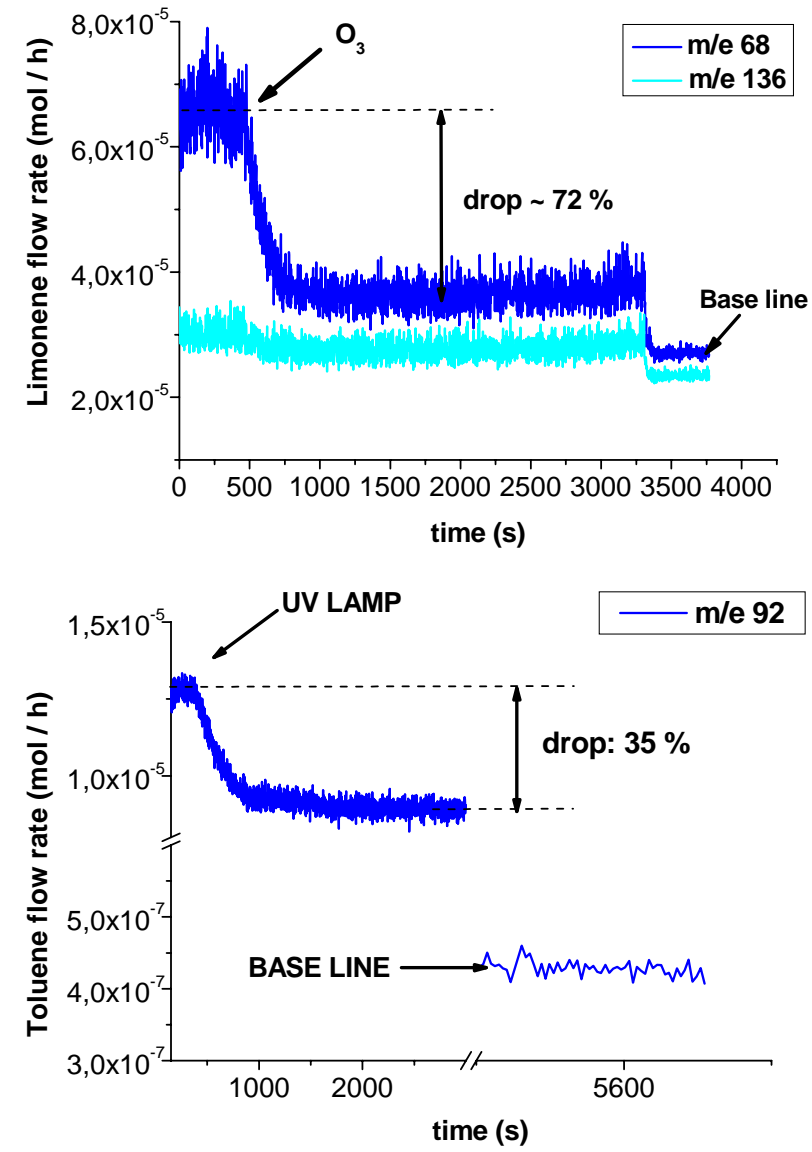

Fig. 3. Time dependence of the hydrocarbon precursor flow rate $(\mathrm{mol} / \mathrm{h})$ in the aerosol flow reactor monitored at $\mathrm{T}=296 \pm 2 \mathrm{~K}$ and (a) $\mathrm{m} / \mathrm{e} 68$ for limonene (experiment LIM3 in Table 1), (b) at $\mathrm{m} / \mathrm{e} 92$ for toluene (experiment TOL3 in Table 1) as a function of time during SOA formation at $\tau=2 \mathrm{~min}, 90 \%$ rh. (b)

ACPD

$5,607-654,2005$

A new experimental technique for determining the SOA surface properties

B. Demirdjian and

M. J. Rossi

(a)

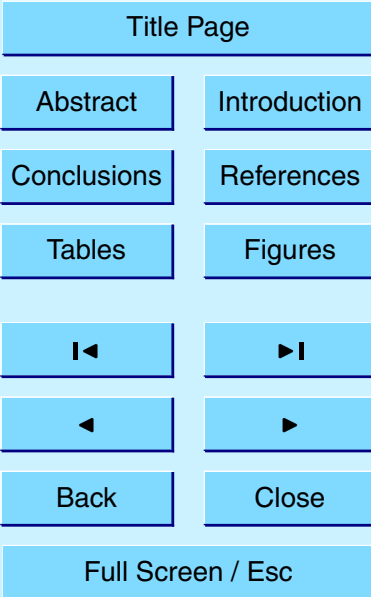

Print Version

Interactive Discussion 


\section{ACPD}

$5,607-654,2005$

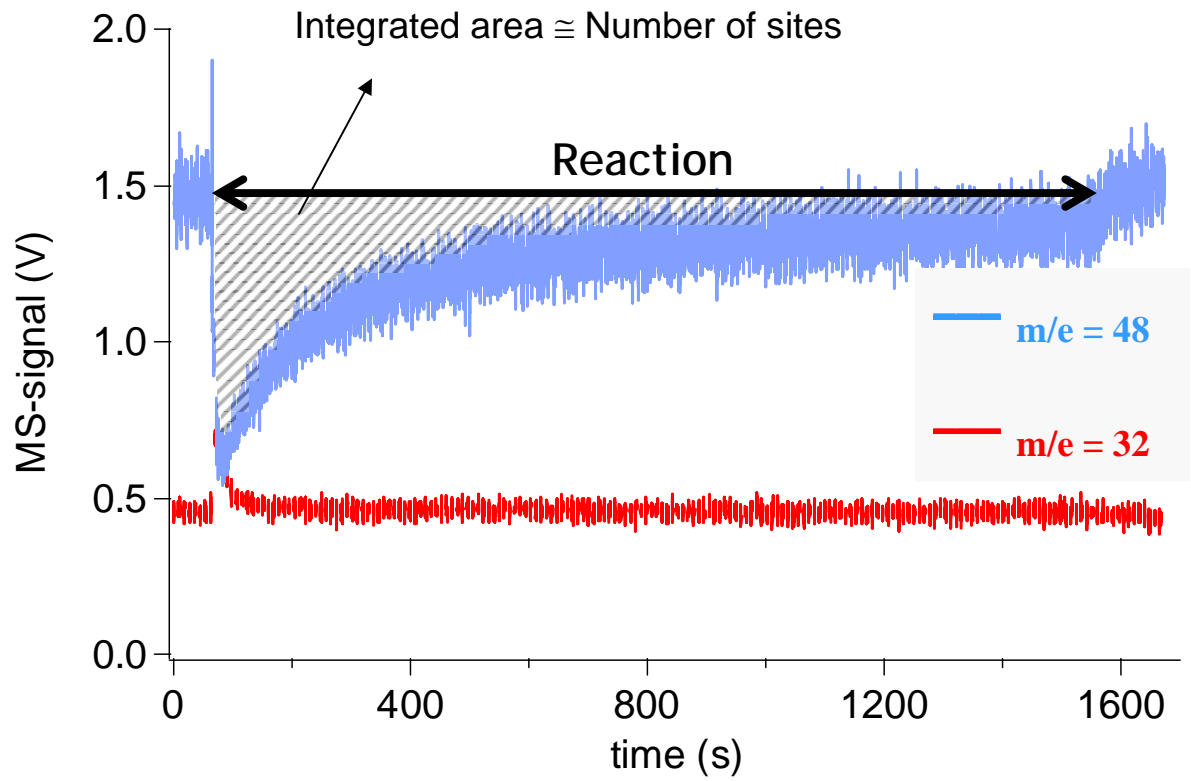

\section{A new experimental technique for determining the SOA surface properties}

B. Demirdjian and M. J. Rossi

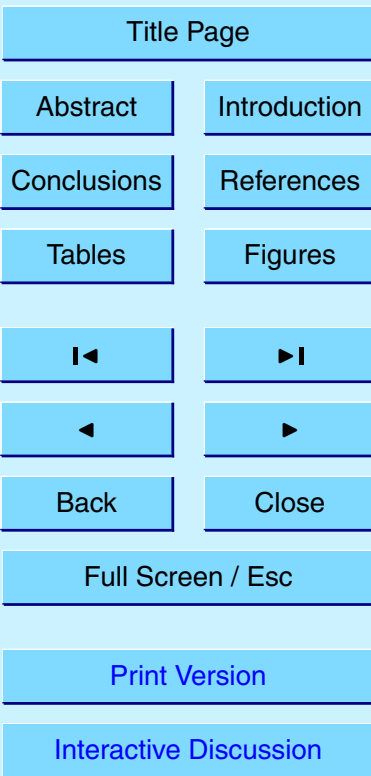

Fig. 4. Typical raw data for a titration experiment using a Knudsen flow reactor at a $1 \mathrm{~mm}$ diameter aperture. It corresponds to the titration of toluene soot particles by $\mathrm{O}_{3}$. The upper $(\mathrm{m} / \mathrm{e} 48$, $\left.\mathrm{O}_{3}^{+}\right)$and lower $\left(\mathrm{m} / \mathrm{e} 32, \mathrm{O}_{2}^{+}\right) \mathrm{MS}$ signals correspond to the $\mathrm{O}_{3}$ and $\mathrm{O}_{2}$ flow rates, respectively, the latter after correction of the $\mathrm{O}_{3}$ contribution at an ozone flow rate $\mathrm{F}_{O 3}^{i}$ of $2.03 \times 10^{15}$ molecule/s. 


\section{ACPD}

$5,607-654,2005$

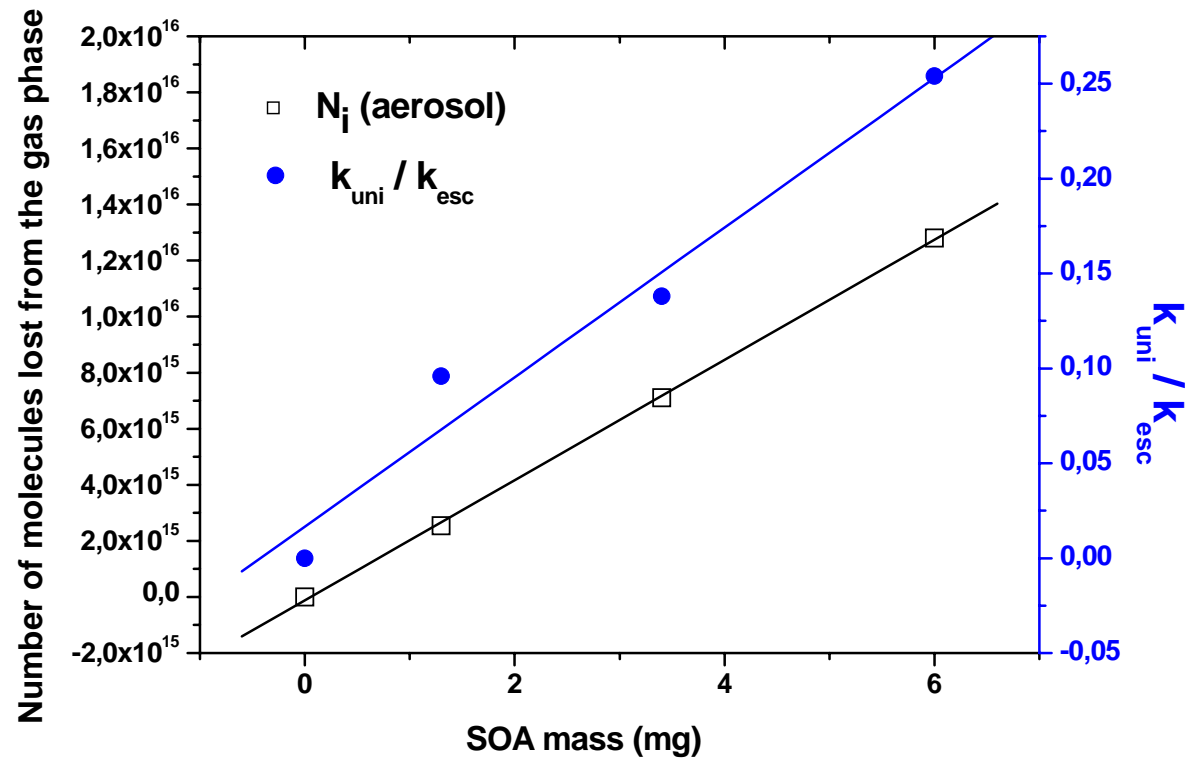

Fig. 5. Dependence of $\mathrm{N}_{i}$ (aerosol) for $\mathrm{i}=\mathrm{N}\left(\mathrm{CH}_{3}\right)_{3}$ (left hand) and of $\mathrm{k}_{\text {uni }} / \mathrm{k}_{\text {esc }}$ (right hand ordinate) on $\mathrm{M}_{S O A}$ of limonene corresponding to experiments LIM4, 5 and 6 of Table 1.

\section{A new experimental technique for determining the SOA surface properties}

B. Demirdjian and M. J. Rossi






\section{ACPD}

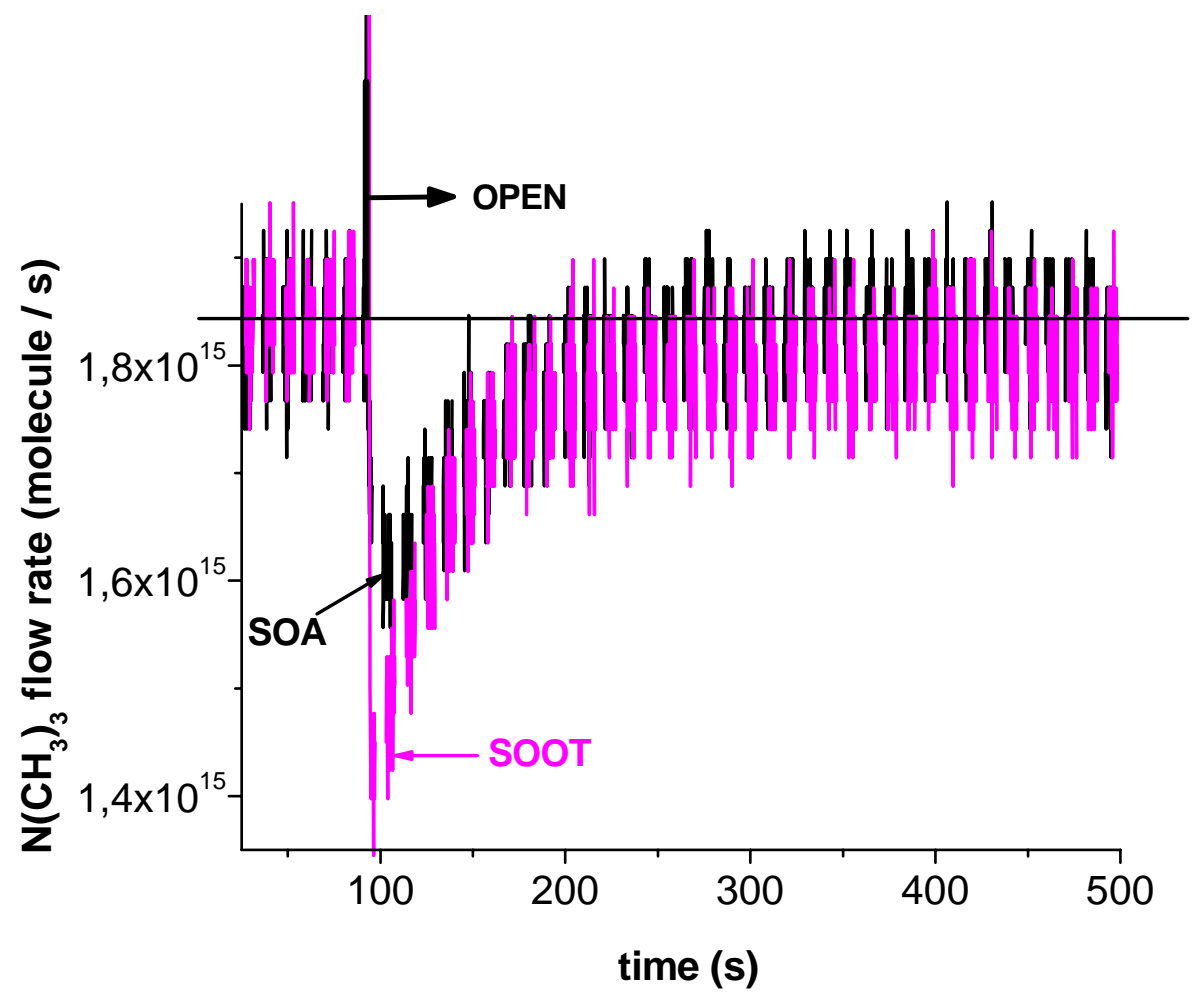

Fig. 6. Absolute uptake rates of $\mathrm{N}\left(\mathrm{CH}_{3}\right)_{3}$ monitored at $\mathrm{m} / \mathrm{e} 59$ on toluene soot and SOA particles obtained at $\tau=2 \mathrm{~min}$, [hydrocarbon] $\cong 1000 \mathrm{ppm},\left[\mathrm{O}_{3}\right] \cong 100 \mathrm{ppm}, \mathrm{rh}=90 \%$ using the $1 \mathrm{~mm}$ diameter orifice $\left(\mathrm{k}_{e s c}=0.023 \mathrm{~s}^{-1}\right)$ at $\mathrm{T}=296 \pm 2 \mathrm{~K}$.
$5,607-654,2005$

A new experimental technique for determining the SOA surface properties

B. Demirdjian and M. J. Rossi

\section{Title Page}

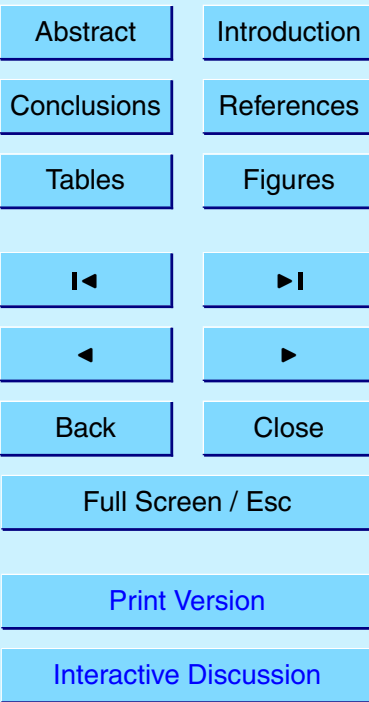




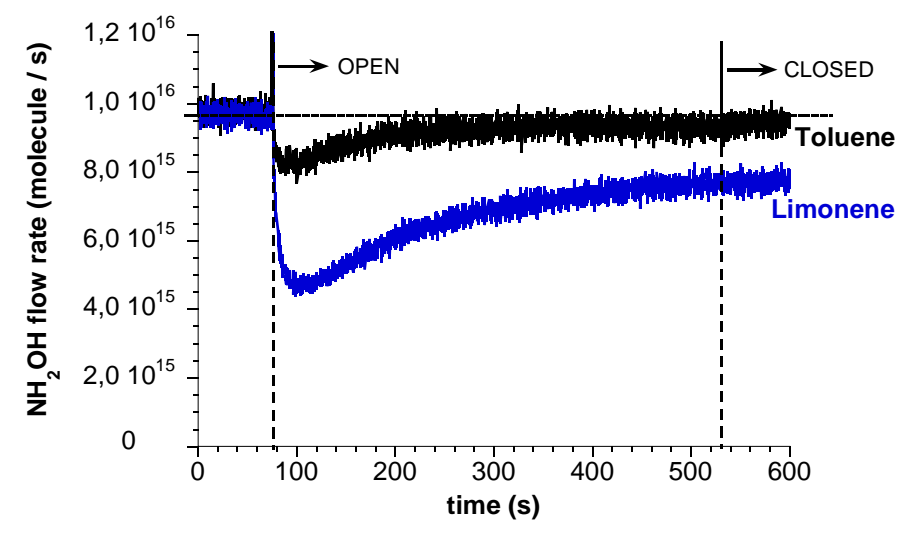

ACPD

$5,607-654,2005$

(a)

\section{A new experimental technique for determining the SOA surface properties}

B. Demirdjian and

M. J. Rossi

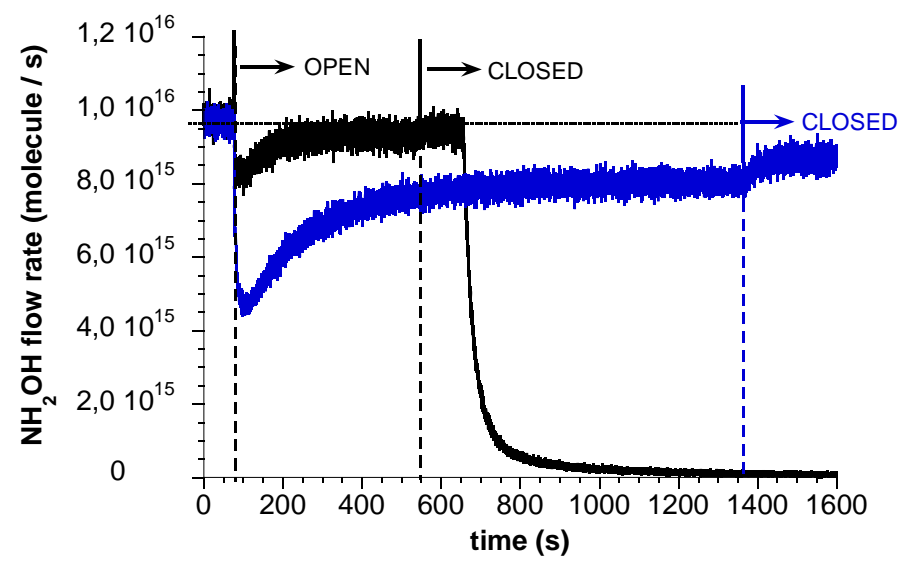

(b)

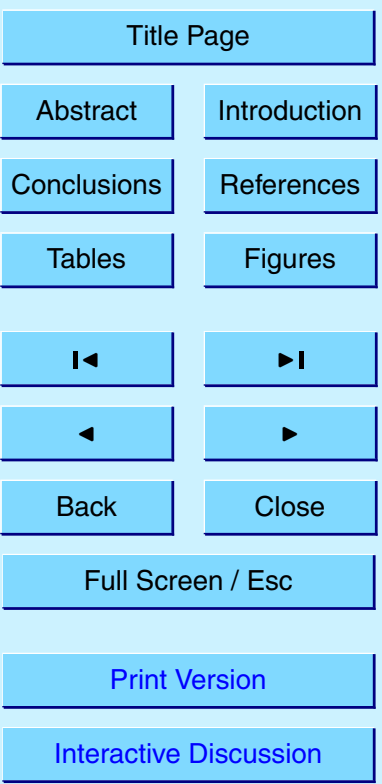

Fig. 7. Absolute uptake rates of $\mathrm{NH}_{2} \mathrm{OH}$ monitored at m/e 33 on SOA generated from limonene (lower trace, blue) and toluene (upper trace, black) at $\tau=2 \mathrm{~min}$, [hydrocarbon] $\cong 1000 \mathrm{ppm}$, $\left[\mathrm{O}_{3}\right] \cong 100 \mathrm{ppm}, \mathrm{rh}=90 \%$ using the $1 \mathrm{~mm}$ diameter orifice $\left(\mathrm{k}_{e s c}=0.031 \mathrm{~s}^{-1}\right)$. Time scale (a) 0 $600 \mathrm{~s}$, (b) $0-1600 \mathrm{~s}$. 


\section{ACPD}

5, 607-654, 2005

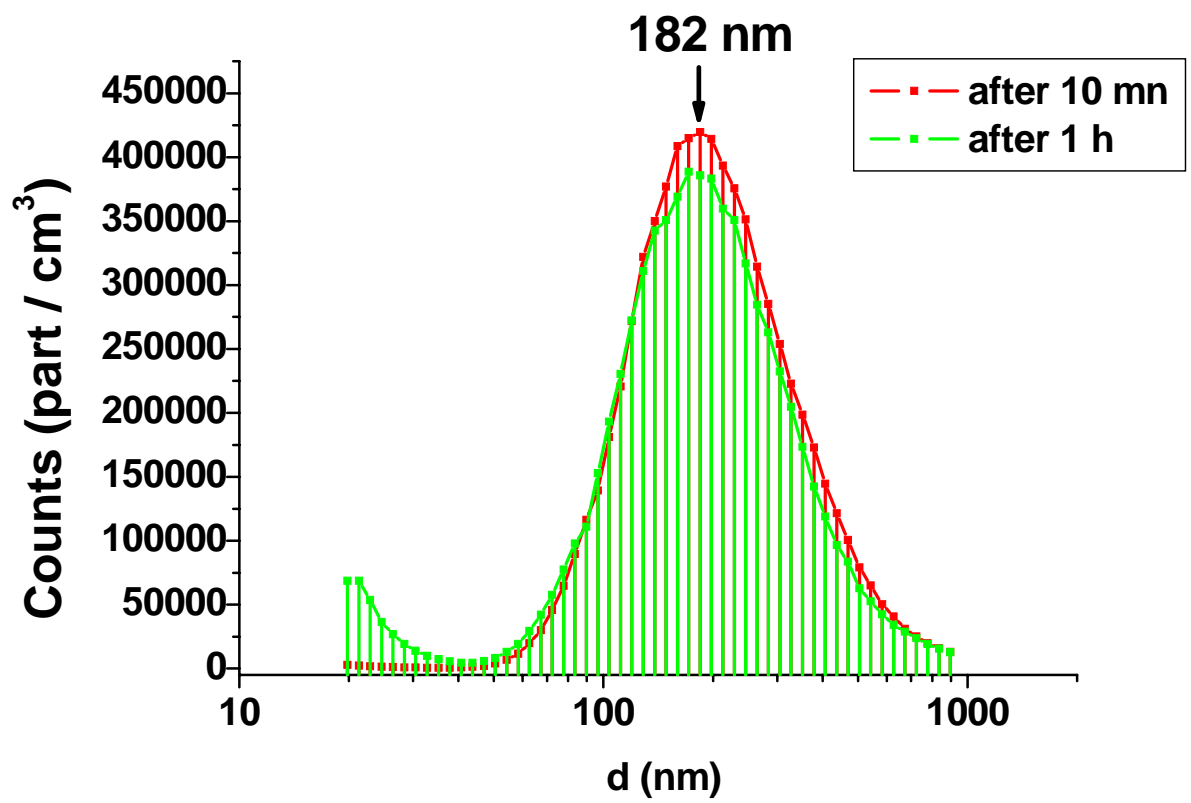

A new experimental technique for determining the SOA surface properties

B. Demirdjian and M. J. Rossi

Title Page

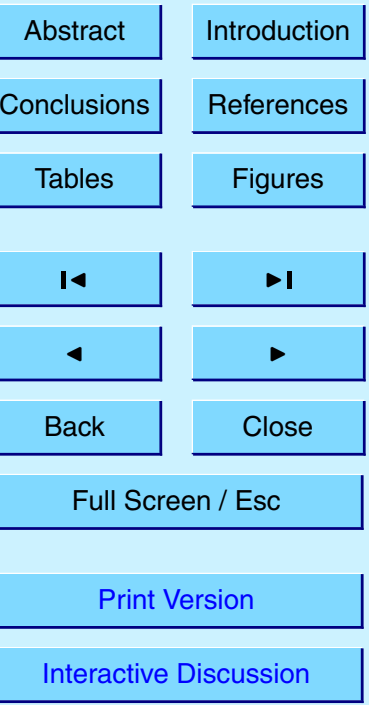




\section{ACPD}

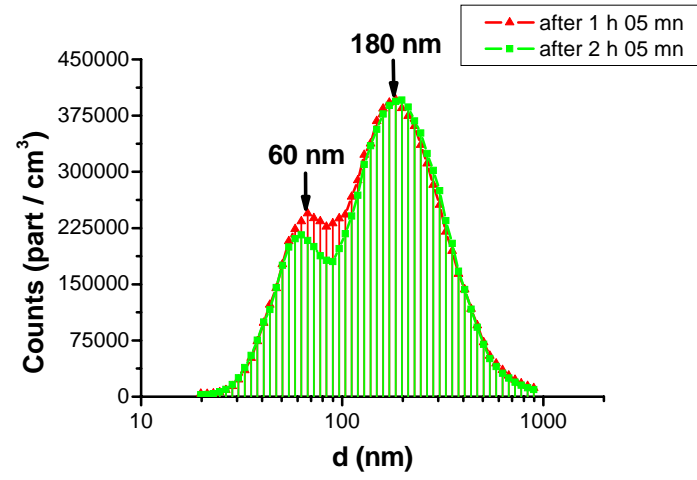

(a)
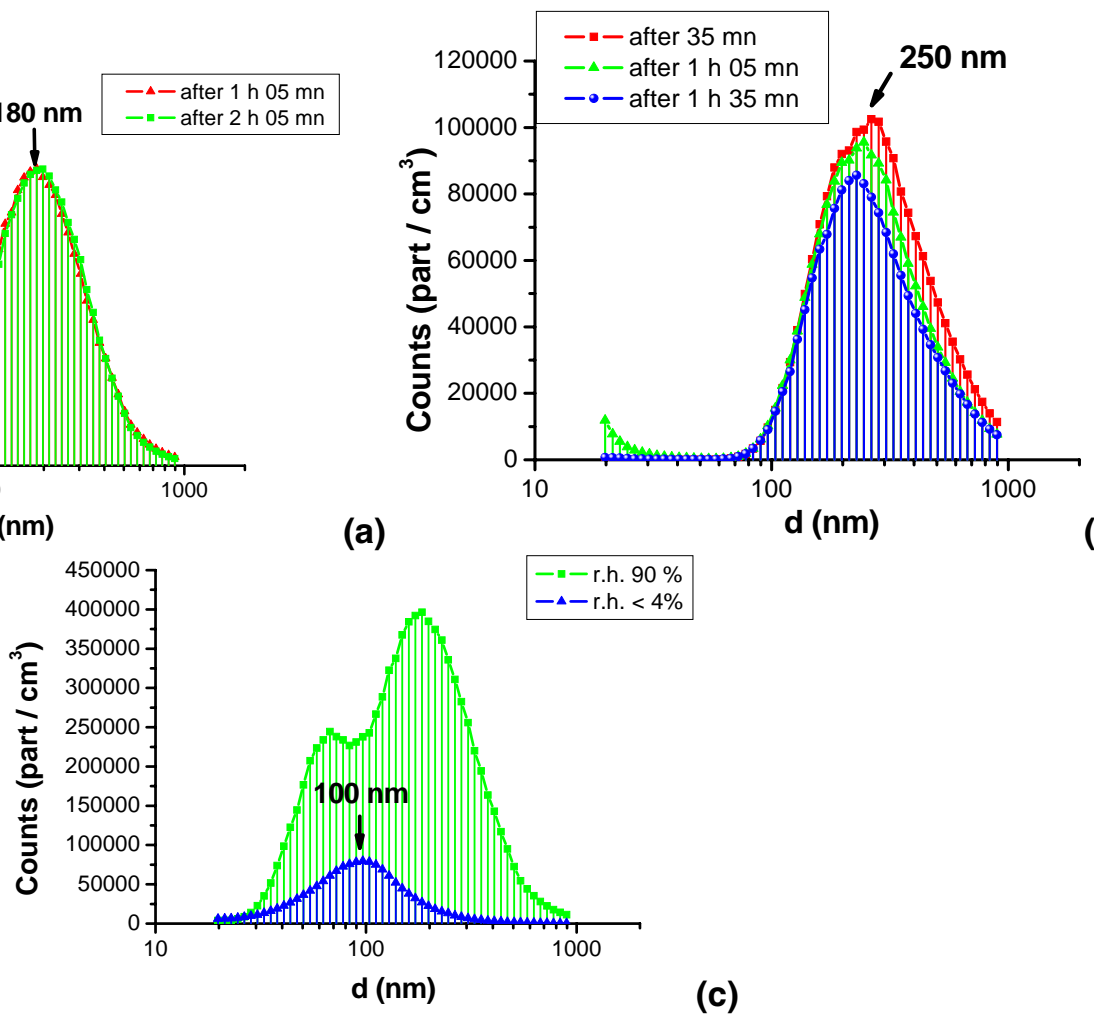

(c)

5, 607-654, 2005

A new experimental technique for determining the SOA surface properties

B. Demirdjian and

M. J. Rossi

(b)

Fig. A2. Size distribution of SOA generated from the photooxidation of toluene at $\mathrm{T}=296 \pm 2 \mathrm{~K}$ and at (a) $\tau=1 \mathrm{~min}, \mathrm{rh}=90 \%$, (b) $\tau=2 \mathrm{~min}, \mathrm{rh}=90 \%$, (c) $\tau=1 \mathrm{~min}$ at $\mathrm{rh}=90 \%$ and $4 \%$. Experimental conditions: toluene flow $=2 \mathrm{ml} / \mathrm{min}$, ozone flow $=10 \mathrm{ml} / \mathrm{min}$, air flow $=250 \mathrm{ml} / \mathrm{min}(\tau=2 \mathrm{~min})$ or $5500 \mathrm{ml} / \mathrm{min}(\tau=1 \mathrm{~min})$, [toluene] $\cong 1000 \mathrm{ppm},\left[\mathrm{O}_{3}\right] \cong 100 \mathrm{ppm}$.

Title Page

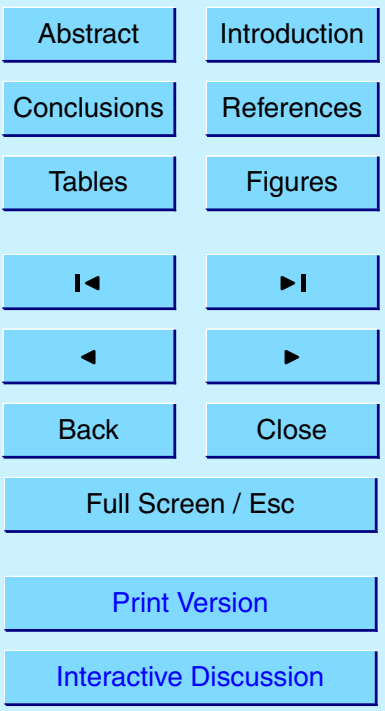




\section{ACPD}

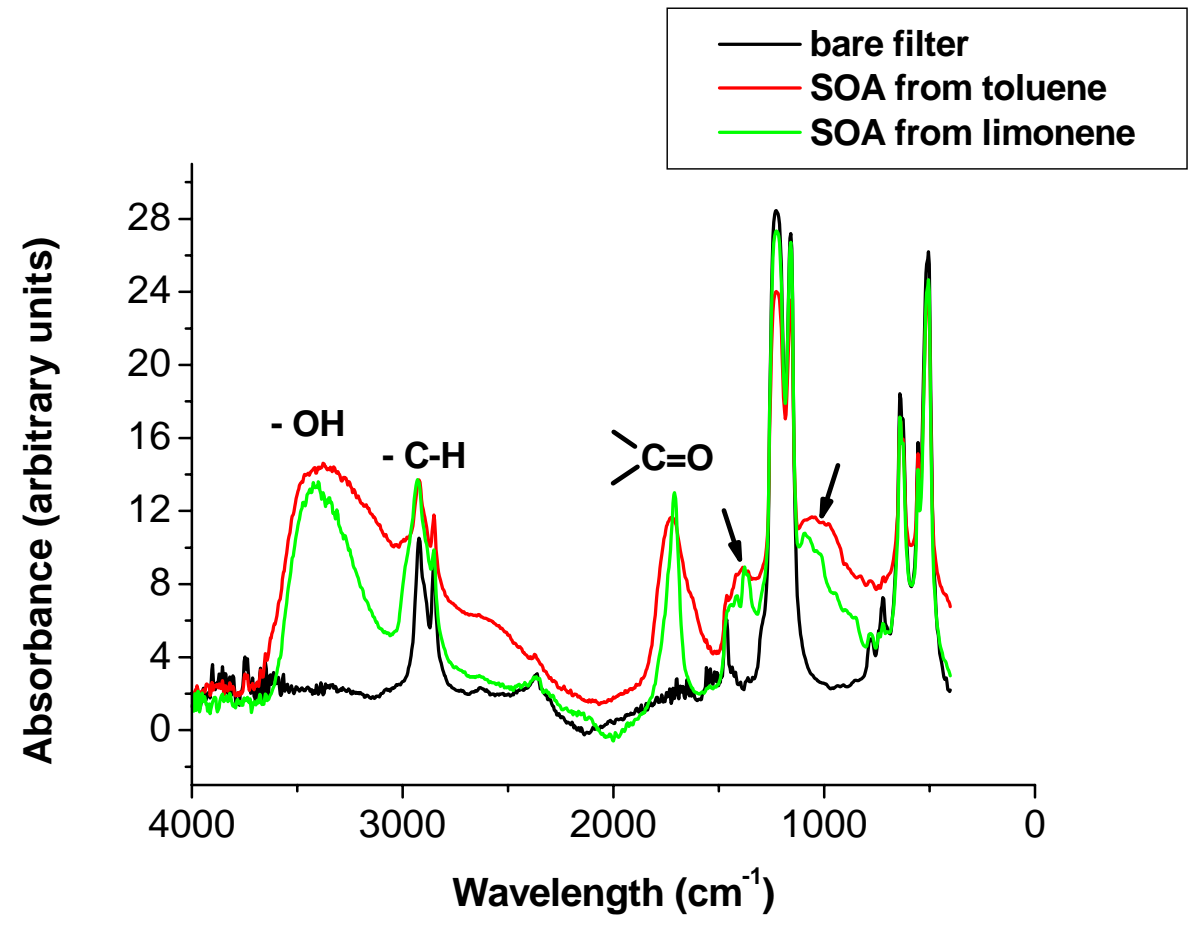

5, 607-654, 2005

A new experimental technique for determining the SOA surface properties

B. Demirdjian and

M. J. Rossi

Title Page

Abstract

Introduction

Conclusions

References

Tables

Figures



from limonene and toluene deposited onto a Teflon membrane filter: [hydrocarbon] $\cong 1000 \mathrm{ppm}$, $\left[\mathrm{O}_{3}\right] \cong 100 \mathrm{ppm}, \tau=2 \mathrm{~min}$ and $\mathrm{rh}=90 \%, \mathrm{~T}=296 \pm 2 \mathrm{~K}$.

Print Version

Interactive Discussion 